\title{
Review of Methods to Probe Single Cell Metabolism and Bioenergetics
}

\author{
Andreas E. Vasdekis ${ }^{1}$, Gregory Stephanopoulos ${ }^{2}$
}

${ }^{1}$ Environmental Molecular Sciences Laboratory, Pacific Northwest National Laboratory, PO Box 999, Richland, WA, 99354, USA.

${ }^{2}$ Department of Chemical Engineering, Massachusetts Institute of Technology, Room 56-469, Cambridge, MA 02139, USA. 


\begin{abstract}
Single cell investigations have enabled unexpected discoveries, such as the existence of biological noise and phenotypic switching in infection, metabolism and treatment. Herein, we review methods that enable such single cell investigations specific to metabolism and bioenergetics. Firstly, we discuss how to isolate and immobilize individuals from a cell suspension, including both permanent and reversible approaches. We also highlight specific advances in microbiology for its implications in metabolic engineering. Methods for probing single cell physiology and metabolism are subsequently reviewed. The primary focus therein is on dynamic and high-content profiling strategies based on label-free and fluorescence microspectroscopy and microscopy. Non-dynamic approaches, such as mass spectrometry and nuclear magnetic resonance, are also briefly discussed.
\end{abstract}




\section{Introduction}

Understanding metabolism and energy flow through cells has recently generated considerable interest. This is due to implications in metabolic engineering and the use of microbes as factories for the production of chemical compounds. Exploratory or optimization investigations to this end commonly take place within the widely available flasks and petri dishes, as well as dedicated bioreactors (Fig. 1a-b). In these, many cells $\left(>10^{11}\right)$ are simultaneously stimulated and their output is collectively analyzed.

In population level studies, however, the performance of individuals is masked and stimuli gradients across the population are enforced due to the geometric boundary conditions of the growth microenvironment. Single cell methods need to be implemented to address these, as recently evidenced by the wide success of single cell genomic and proteomic approaches. Herein, we review methods for studying single cell physiology - specifically metabolism and bioenergetics - where cells are now treated as isolated biochemical factories, thus enabling the precise measurement of (a) their metabolic profile and (b) culture heterogeneity, as well as (c) the effect of the microenvironment.

Despite their potential in gaining a unique insight in cell metabolism, it is important to note that care has to be taken when designing single cell experiments and interpreting results. In addition to the need for statistical significance, the differences between experimental conditions at the population-level and the micro-volume that contains an individual cell need to be considered. Such differences include population-level characteristics that are challenged by isolating an individual, such as cell-to-cell communication (e.g. via quorum sensing), spatiotemporal gradients of stimuli and the co-existence of cells in various growth stages. 
The review is divided in two parts. In the first, we discuss methods for biomass manipulation down to the single cell level. This is a critical step, as the volume of a typical microbial cell (bacteria or yeast) is approximately 12 orders of magnitudes smaller than common reactor volumes ( L). This is highlighted in Fig. 1a-c in the scale comparison between typical industrial and laboratory scale reactors with that of an individual Yarrowia Lipolytica yeast cell. Thus, the study of single cells necessitates appropriate sampling and manipulation to address this considerable volume mismatch. This can be achieved via multiple strategies, both stochastic (e.g. serial dilutions) and deterministic (e.g. micromanipulators).

In the second part of the review, we discuss methods for probing the metabolism and bioenergetics of single cells. Areas such as single cell mass-spectrometry, bioimaging, optical sensing and spectroscopy are covered. The applications of such methods, such as strain selection, profiling intracellular metabolites, and dynamic metabolic mapping (e.g. respiration monitoring), will also be discussed for each individual technique.

\section{Single Cell Manipulation}

The sampling and manipulation of cells down to the individual has been of substantial interest since the very beginning of Life Sciences. The first recorded single cell study involved the use of a micropipette to place a single Erwinia amylovora cell on an apple blossom and study its infectivity [1]. This technique - with minor modifications - served with great success the early physiology, [2] genetics [3] and microbiology [4] studies. Since then however, a significantly wider variety of methods has emerged. These are primarily based on modern micro- and nanotechnologies involving advanced fabrication, materials and chemical functionalization methods. 
Herein, our objective is to highlight the most recent developments in single cell manipulation, as well as pioneering ones; it is also worth noting that excellent reviews exist on similar topics [515]. First, flow-through methods will be discussed, namely methods in which single cells flow continuously in an ordered manner during their analysis. This section will be followed by confinement techniques that enable cell isolation and confinement in zero-, one, or twodimensions (Fig. 1d) [12]. Such confinement techniques can be further divided into permanent and reversible or dynamic ones and can be based on both chemical and physical approaches. The section will conclude with a comparison between these approaches.

A critical aspect of both flow-through and confinement strategies is the enabling fabrication method, which in the majority of examples is based on Soft Lithography. The latter will not be discussed in detail in the present review and the potentially interested reader is referred to recent excellent recent reviews on the topic [16-18].

\subsection{Flow-Through Methods}

Flow cytometry and droplet microfluidics are the two most common methods of flow-through analysis. While both are high-throughput techniques [19], their difference is that the droplet encapsulated cells experience a restricted and personal microenvironment, while in flow cytometry cells experience similar nutrient and stimuli initial concentrations. These methods are

rather well established; however, they recently enabled immense strides in single cell phenotypic analysis, namely the identification and analysis of metabolically distinct individuals from an isogenic population using both droplet microfluidics [20] and flow cytometry [21]. 


\subsubsection{Flow Cytometry}

Similar to its first ever designs [22, 23], most modern flow cytometers contain a nozzle and a flow chamber. These, through the principle of hydrodynamic focusing, guide individual cells to flow sequentially through a microanalysis location, mostly optical (i.e. fluorescence or light scattering) or mass spectrometry based. In this way, high content screening at the single cell level can be achieved at rates as high as $10^{4}$ cells/s (Fig. 2a) [24, 25]. In minor modifications, the cells can also be sorted depending on their fluorescent (or other) properties, thus forming the socalled Fluorescence Activated Cell Sorters (FACS).

Flow cytometers are widespread and accessible instruments, with applications ranging from the most early studies on biological noise (stochasticity) [26-28], to more recent investigations in metabolic engineering [29]. Additionally, research and development on cytometers is still an active research field, with recent advances in instrument miniaturization and the introduction of novel types of cell interrogation. Microfabricated cytometers (microcytometers) emerged with the advent of microfluidics [30], aiming primarily at reducing capital investment requirements [31]. Another advantage of scaling down cytometers is the ability to integrate more complex functionality, such as more efficient cell transport and sorting [32], as well as more efficient single cell analysis [33].

Regarding the available types of interrogation, most conventional cytometers analyze and sort cells based on their fluorescent and light-scattering properties. More recently, especially in microcytometers, the use of dielectric [34] or Raman [35] spectroscopies, as well as the measurement of cell capacitance [36], impedance [37] and mechanical properties [38] have emerged. Highly-multiplexed single cell analysis using flow cytometers recently became 
available through the 'mass cytometry' based on inductively coupled plasma (ICP) mass spectrometry [39].

\subsubsection{Droplet Microfluidics}

Droplet microfluidics (including digital microfluidics) is essentially a two-phase fluidic microsystem formed via the interaction of two immiscible fluids, specifically by shearing one into the other [40-42]. Droplets in microfluidics offer several distinct advantages, forming thus an ideal assay platform for screening or other purposes [20]. These advantages include the generation of highly mono-disperse [43] and size-variable microreactors [44], which can additionally be transported in a dilution free and zero cross-contamination manner [45]. More recently, techniques for accurate mixing of pL volumes using droplets have been reported [4648].

A wide variety of methods to encapsulate single-cells into individual droplets also exist (Fig. 2a, b) [49-52], including droplets made of hydrogels such as agarose [53]. Thus, the aforementioned compartmentalization-driven advantages of droplets can translate into unique features in investigating single cell physiology $[54,55]$, and genomic content [56-58]. The first is that cellsecreted molecules remain confined within the volume of the droplet, and thus can rapidly reach detectable concentrations $[20,59,60]$. The second advantage is the ability to rapidly mix minute $(\mathrm{pL})$ volumes of reagents, hence enabling reduced reagent consumption [61], as well as the high-precision timing of reaction kinetics. The latter was recently demonstrated by identifying mutants producing enzymes with improved productivity and activity [62].

One disadvantage of droplet based single cell analysis compared to conventional flow cytometry is the stochastic nature of encapsulating cells in droplets, which may reduce cell throughput [63]. On the other hand, single cell confinement in microdroplets allows for identification of cells with 
superior properties of secreting a product metabolite and identifying genetic elements that are responsible for an elevated production phenotype of secreted products [20]. No other methods are available to identify such super-producing cells.

\subsection{Permanent Confinement}

Permanent confinement methods enable the irreversible and non-dynamic positioning of an individual cell or of a population of single cells. This, generally, can be achieved via chemical or physical potentials (or barriers) that forbid cell motion in all, or in specific directions. Depending on the type of confinement, the cell position may fluctuate within controlled multicellular or subcellular distances (i.e. a few $\mu \mathrm{m}$ 's down to a few $\mathrm{nm}$ ) in one-, two- or even three dimensions (Fig. 1). Such methods will be reviewed in this section and classified depending on their confinement size and dimensionality.

\subsubsection{D Microcavities}

In this embodiment, a micron-scale topographic cavity - or an array of cavities - is engraved on a surface, thus confining isolated cells in that microenvironment, however, without generally restricting their motion. Microwells and microchemostats belong to this category, offering confinement levels of generally cellular resolution.

Microwells: A type of microcavity is a lithographically defined microwell (Fig. 3a) [64]. In these, a cell suspension is introduced over the microwell array, and cell loading in the microwells commonly occurs by sedimentation (gravity) [65]. Single cell immobilization is ensured by employing appropriate seeding cell concentration, seeding time and microwell dimensions [66,

67] (Fig. 3b). It is worth noting that this type of cell confinement is very common, as it is 
compatible with a wide range of microfabrication and functionalization techniques, as well as types of materials, including $\mathrm{SiO}_{2}$ [68], poly(ethylene glycol) [69], PDMS [70], (including functionalized PDMS [71]), functionalized hydrogels [72], the photoresist SU8 [73], and solid agarose [74]. Up to 3600 cell traps have been reported using microwells [75].

Microchemostats: Microfabricated chemostats enable continuous and dynamic stimuli delivery and product removal from the microenvironment surrounding the confined cells [76, 77]. In one of the first of such demonstrations, Khademhosseini et al. reported an array of microwells impregnated at the bottom surface of a microfluidic channel. The array was able to trap populations of single mammalian cells simply by controlling the flow conditions [78] (Fig. 3c). This architecture was recently evolved into microwell arrays separated by the microfluidic channels via hydrogel layers [79]. To enable handling of smaller and more motile cells, Groisman et al. developed an array of microchambers $\left(\sim 100 \times 100 \mu \mathrm{m}^{2}\right)$ connected to apertures whose diameter was flow dependent [80]. This enabled bacteria loading and at high flow-rates (large aperture), and subsequently trapping them at lower flow rates (smaller aperture). Similarly, 'Lobster Traps' were demonstrated in a crosslinkable bovine serum albumin (BSA) matrix; in these, - following cell seeding - the loading apertures permanently seal by raising the temperature and forcing the BSA matrix to expand [81].

\subsubsection{Confinement in 2D}

Single cell populations are most commonly studied in microsystems that enforce 2D confinement, namely allowing cell motion within a $2 \mathrm{D}$ plane. This is typically achieved by volume exclusion by geometrically minimizing the available space in the third dimension, thus ensuring the formation of a $2 \mathrm{D}$ cell monolayer. In one of the earliest reports of this type, 
Cookson et al. reported the Tesla microchemostat $(T \mu C)$ by integrating large seeding microchannels with a $4 \mu \mathrm{m}$ thick trapping region (Fig 4a) [82]. This size mismatch enabled the stable trapping of many single cells of Saccharomyces cerevisiae within a single focal plane for more than 24h (Fig 4b). This basic architecture has found many applications in long-term bioimaging of both eukaryotic cells $[83,84]$, and bacteria $[85,86]$. More recently, Dénervaud et al. reported a massively parallel array of microchemostats capable of confining 1,152 individual cells [87]. In this embodiment, a DNA spotter was used to array single cells on a surface and subsequently align them with individual chambers interconnected to media delivery microchannels.

Despite their simplicity, most 2D confinement architectures may suffer from significant build-up of chemical gradients of nutrients and waste throughout the cell monolayer which may lead to significant phenotypic heterogeneity within the colony [88]. More recent 2D confinement architectures have partially addressed this. In one approach, some level of environmental control was possible by including multiple inlet and outlet microchannels for the supply of nutrients and waste removal [89] (Fig 4c). It is worth noting that the effect of nutrient gradients on bacterial metabolism and chemotaxis has also been investigated in pore-scale microfluidic models, which elegantly simulate subsurface and bioremediation conditions [90-92].

\subsubsection{Confinement in 1D}

In this embodiment, the cells are contained within a linear track, thereby placing strict boundary conditions for motion and proliferation in directions perpendicular to the track itself [93] (Fig 1d). This enables more straightforward tracking of both individual cells and their lineages in comparison to $2 \mathrm{D}$ or 3D growth, as illustrated in Fig 4d. In the earliest report of this type, Balaban et al. grew E. coli cells within grooves of dimensions similar to the width of the bacteria 
[94]. The grooves were molded in PDMS and bonded to a membrane through which nutrients and stimuli were delivered to the cells.

Subsequent attempts aimed at facilitating cell loading and nutrient supply. Regarding the former, in one approach, the Weitz group integrated the tracks with indentations of sub-cellular dimensions [95]. This prevented the cells from flowing through, thus enforcing their trapping within the track. Upon loading, the hydrodynamic resistance of the apertures increased ensuring single cell occupancy. In a more multiplexed assay - the 'mother machine' - cell seeding took place by diffusion from much larger microchannels, thus infilling approximately 4000 growth tracks [96]. Regarding nutrient supply, this has been optimized from the initial designs by employing agarose-made linear tracks instead of the more conventional PDMS [97]. The inclusion of media carrying trenches next to the tracks [98], as well as the use of channels of an orthogonal - asymmetric - geometry have also been reported [99]. Advanced microfabrication techniques based on electron beam lithography allowing the fabrication of much narrower tracks have been recently reported, primarily for the 1D confinement of much smaller bacteria [100].

\subsubsection{Confinement in 0D}

Under 0-D confinement, the cells are strictly immobilized at a fixed location within only minor sub-cellular position fluctuations. Generally there are two ways of achieving this: the more traditional approach involving gels and surface functionalization strategies, as well as more recent ones based on micro- or nanofabricated filter beds, through which the cell suspension is flown. We will employ early microfluidic nomenclature of the latter strategy, namely percolation filtration, $[101,102]$ in which the filter exhibits dimensions smaller than the cell in order to trap the targets under continuous flow-driven, shear pressure. 
Axial percolation filtration $(A P F)$ : The cell suspension flows perpendicular to the filter bed in this embodiment. In one of the earliest reports of this type, Wheeler et al. integrated a microfluidic 'T-junction' with a micron-scale trap: a stagnation point develops at the center of the T-junction (Fig. 5a), which locally stabilizes the flow stream and cells gently land and stay in the dock [103]. In a subsequent, pioneering report, Di Carlo et al. developed an array of hydrodynamic trapping structures with a U-shaped geometry (Fig. 5b) [104]. The U-shaped trapping site contains a narrow aperture smaller than the cell size, preventing it from flowing through and enforcing to reside within trap. This basic design later evolved to enable the integration of the trap with a pneumatically isolated microchamber [105], as well as trapping of individual bacteria [106, 107], including architectures capable of removing the daughter cells [108]. Similarly, instead of the U-shaped geometry, monolithic PDMS pads have been recently reported (Fig. 5c). These also enable selective trapping of mother and release of daughter cells, respectively [109].

Lateral percolation filtration $(L P F)$ : In this approach, in essence an evolution from APF, the cell suspension flows parallel to the filter plane. LPF is generally based on the 'basin-style' design, where the trapping microstructures are aligned perpendicular to the flow direction (Fig. 5d). Sophisticated hydrodynamics enable a pressure gradient to build up between loading and trapping sites, forcing the cells to move into the traps. This pressure gradient is reversed once a cell is trapped, thus preventing secondary cells from entering the same trapping site. This was initially demonstrated by Tan et al. for microparticles [110], and later evolved into a highthroughput microarray of more than 2000 traps $[111,112]$, as well microsystems for co-culturing heterotypic cells [113]. It is worth noting that both the APF and LPF confinement can be applied to immobilizing cells encapsulated within droplets, instead of cells by themselves $[114,115]$. 
Hydrogel encapsulation: The encapsulation of living cells in hydrogels is a very traditional approach, with a wide range of available materials and gelation stimuli (agarose, gelatin, poly(ethylene glycol), alginate etc.) [3]. In one embodiment, the cells are deposited on a slide and the gel is placed on top and subsequently solidified [116]. Image analysis enables cell tracking over multiple generations, including the dynamic mapping of their gene regulatory networks and phenotype by imaging [117, 118]. Alternatively, prior to gelation, the cell suspension may be mixed with a hydrogel solution - a very common immobilization technique for maintaining a 3D culture architecture in immune and regenerative medicine $[119,120]$. While practical, hydrogel encapsulation suffers from two shortcomings, namely the uncontrolled cell growth and resulting challenge of single cell tracking (Fig. $\mathbf{4 d}$ ), as well as limited nutrient and stimuli exchange over time. The latter has been recently addressed via the microfluidic integration of hydrogel encapsulated cells; in this way, small molecules present in the microfluidic solution surround and subsequently diffuse into the gel, thereby enabling a dynamic microenvironment chemical control. In such approaches, hydrogel gelation by UV light for integration inside microfluidic networks [121-123], as well as solidified gels integrated vertically with microchannels, have been reported [124]. Gelation in these methods may involve exposure to high temperatures or UV light [125], or the potentially safer ion-based crosslinking [125].

Surface - cell interactions: Cell-surface interactions still receive substantial attention since they are involved in areas such as biofilm formation, antifouling of implants and tumor architectures [126-128]. Such interactions may arise from physical (e.g. Van der Waals), or biochemical forces (e.g. protein, lipopolysaccharides and DNA mediated), and their combinations. Despite ongoing investigations, surface tethering of single cells has been employed for many years and such key examples in single cell physiology technologies will be highlighted. 
In an early example, polylysine coated nitrocellulose membranes were employed for immobilizing S. cerevisiae and Escherichia coli for up to 4 hours, while continuously releasing their newborn cells $[129,130]$. The technique, termed 'baby machine', is the chemical equivalent of the recently reported 'dissection platform' [131]. Polylysine is water soluble and thus compatible with PDMS, which has enabled many microfluidic investigations on single bacteria $[132,133]$. Cholesterol containing co-polymers, and APTES (aminopropyltriethoxysilane), are also water soluble and have been shown to be straightforward methods for tethering yeast in microfluidics $[134,135]$.

Chemical patterns on surfaces will in turn enable patterned immobilized cells even down to the single cell level [136, 137]. Many techniques exist for generating such surface chemical patterns, such as microcontact printing of self-assembled monolayers (SAMs) [138], which can also be reversed electrochemically [139]. Photolithographically defined SAM patterns using UV [140] or visible radiation [141], as well as electrochemical [142] and photocatalytic methods, have been reported more recently [143]. Again, the microfluidic integration of chemical patterns is an important aspect. To this end, chemical patterning in-situ has been recently demonstrated [144], including the integration of metabolic monitoring capabilities using electrochemical $\mathrm{pH}$ sensors [145].

While in most cases, functionalized surfaces have been employed, bare - non functionalized coverslips have also been shown to provide a strong enough tether both for yeast [146] and bacteria [147]. Cell-specific tethering is also possible, for example, via antibody, protein, or peptide specific adhesion, as recently reviewed elsewhere [148].

Cell-surface interactions are the simplest method to immobilize single cells with high viability. However, care has to be taken in selecting the appropriate strategy as phenotypic changes may 
occur upon surface contact, such as the increased EPS matrix in E. coli [149]; for a more detailed discussion on this topic, the reader is referred to the following - bacteria focuses - review article [127].

\subsection{Dynamic Confinement}

In dynamic confinement, single cells or populations of single cells are immobilized and released upon demand. Applications of this type usually involve the post-trapping analysis of the target, such as lysis mediated proteomics and transcriptomics. External stimuli (optical, electrical, acoustic etc.) and recently passive microstructures that generate a reversible trapping potential are commonly employed to this end. These approaches will be reviewed in this section and classified depending on the potential type they employ.

\subsubsection{Mechanical Micromanipulation}

Different types of mechanical micromanipulation exist, such as hydrodynamic, acoustic, or the use of pneumatic valves in microfluidics. Each type is reviewed separately below.

Pneumatically Isolated Microcavities: This is a special class of microcavities formed by two valves that pneumatically seal a portion of a microfluidic channel (Fig. 6a). The elastomeric nature of PDMS and multi-layer soft lithography are critical in such embodiments [150]. The cells are generally in-between two valves and can be released by opening the valves [151]. Due to their simplicity, and lab-on-a-chip compatibility, this type of dynamic microcavities has made a tremendous impact in elucidating biological noise [152] and in single cell sequencing and transcriptomics [153-155]. 
Hydrodynamic: Hydrodynamic manipulation is generally achieved in contact and non-contact methods. In the former, we recently demonstrated that trapped cells in percolation filters can overcome the trap barrier simply by increasing the flow rate [106]. In this way, the drag force increases, eventually leading to cell escape (Fig. 6b). Regarding non-contact methods, forms of this type include microvortices [156] and stagnation point microflows [157]. In microvortices, microeddies are generated in the proximity of solid boundaries under fluid oscillation conditions (Fig. 6c) [158], with reversible trapping occurring at the eddie center [159]. Stagnation point trapping occurs at the junction of two streams (Fig. 6d) [160]. By combining active flow control and microscopy, a condition of zero force exerted on a cell can be reached, leading to stable trapping at the junction [161]. Non-contact methods are generally simpler; however, they do not enable strict immobilization with the cell position fluctuating with time.

Acoustic: Acoustic manipulation is based on ultrasonic standing waves and was discovered in the early seventies [162]. In these, ultrasonic transducers, which generate acoustic waves and hence trapping forces, are integrated with microfluidics [163]. Acoustic trapping has shown to preserve cell viability, despite the significant temperature increase $\left(\sim 15^{\circ} \mathrm{C}\right)[164,165]$. More recently, the acoustic trapping power requirements were substantially reduced by employing piezoelectric substrate and surface acoustic waves (SSAW) [166].

\subsubsection{Optical Micromanipulation}

Optical Tweezers: Optical tweezers (OT) is arguably the most common form of single cell dynamic manipulation $[167,168]$. In OT's, a laser beam is focused in the cell medium, generating a strong electromagnetic field gradient that pulls individual cells towards the beam center (Fig. 7a) [11], where they remain for prolonged durations [169]. By passing the optical beam through a spatial light modulator [170], or a microlens array [171], multiple focused spots 
are generated, hence giving rise to multiple trapped cells-recently as up to as many as 200 have been reported. The optical focused spot can be also moved, enabling thus the deterministic transport of the trapped cells. This has been shown to conveniently enable the isolation and transportation of single cells within microfluidic [172] or hydrogel growth chambers [173]. A unique advantage of OTs is that they immobilize single cells away from surfaces, and are thus very popular with Raman microspectroscopy [174].

Scattering Forces (Radiation Pressure): Focused optical beams may also induce weak repulsive forces along the light propagation axis, [175] a concept that has also found multiple single cell applications [176]. Single cell immobilization is possible at the center of two lightly focused, counter propagating laser beams, an approach frequently referred to as the 'dual beam trap' (Fig. 7b) [177]. Alternatively, scattering forces may be employed to force a trapped cell out of position to its release; this approach was demonstrated by Kovac et al. for forcing cells outside of their trapping microwells (Fig. 7c) [178]. Recently, single cell trapping and transport was demonstrated using integrated optical waveguides and resonators. This approach reduces the experimental complexity as well as enabling deterministic light propagation and cell transport along a lithographically defined optical waveguide $[179,180]$.

Optoelectronic Tweezers: In optoelectronic tweezers (OET), the cell suspension is introduced in between two electrodes, one of which is additionally coated with a photoconductive layer. Upon illumination, a non-uniform electric field is generated between the two electrodes, which in turn induces a dipole and a 'dielectrophoretic' force on the cells that traps them on the photoconductive surface [181]. Due to their low light intensity requirements and ability to employ spatial light modulators to generate multiple excitation locations, OETs can generate massively high-throughput trap arrays, with up to 15,000 trapping sites demonstrated [182]. 
Recent progress in OET has enabled their microfluidic integration [183], as well as their further simplification and miniaturization by employing alternative illumination strategies such as micro-LED arrays [184].

Light Stimulated Hydrogels: In section 2.2.4, hydrogels were discussed in the context of OD confinement. However, hydrogels can be also optically degraded and thus enable dynamic control of their cell confining potential [185]. Alternatively, hydrogels can be also optically polymerized, as recently demonstrated in combination with microwell trap arrays: the trapped cells were covered with a photosensitive hydrogel, which was selectively illuminated and solidified apart from locations where target cells resided; these could then be recovered by simple washing (Fig. 7c) [186].

Photothermal: Photothermal single cell manipulation is less common, but has been employed to release trapped cells in microfluidic trap arrays, as reported in the seminal work by Tan et al. [110]. This involved the integration of an aluminum pad in the cell trap location. Upon illumination with a laser beam, the local temperature around the pad was raised, thus inducing a bubble that forces the cells to overcome the trap potential and be released.

\subsubsection{Dielectrophoretic Micromanipulation}

Similar to the Optoelectronic Tweezers case, in dielectrophoretic (DEP) manipulation, an electric field is generated in the vicinity of microfabricated electrodes; this then induces a dipole in the cells in close proximity [187]. This forces the cells to experience a Coulomb interaction and a resulting trapping force. DEP applications involve cell screening, sorting or transport [188], as well as immobilization, by employing specific quadrupole, octopole or ring electrode geometries

(Fig. 7d) [189-191]. In electrode arrays, the cell may also be transported from electrode to 
electrode under the application of specific voltage patterns [192]. Recently, DEP forces were employed to release immobilized cells from a microfluidic trap array [193].

Due to the need of electrode integration, DEP trapping microsystems usually require complex fabrication. Buffer heating effects may also occur due to power dissipation at the electrodes, which was recently measured to reach up to $20^{\circ} \mathrm{C}$ [194]. Despite such shortcomings, reversible DEP immobilization has found applications in single cell metabolic studies, such as bacterial proliferation in controlled microenvironments [195].

\subsubsection{Magnetic Micromanipulation}

In magnetic micromanipulation, magnetically labelled cells are placed in the proximity of magnets [196]. The need for magnetically labelled cells was recently successfully eliminated by using paramagnetic buffers [197]. Gach et al. demonstrated cell release in magnetic polymer microwells [198], where under the action of a magnetic field, selective removal of an individual microwell was possible (Fig. 7e). To eliminate cell, buffer, or microwell labelling, magnetic nanowires or microparticles were recently shown to trap single cells; the microparticles rotate under the action of a rotating magnetic field, thus generating microvortices and trapping single cells within $[199,200]$.

\subsection{Summary}

As discussed in this section, a wide variety of techniques exist, each with its own resolving abilities and target information (e.g. high-throughput versus dynamic analysis, or high/low content screening, mammalian/microbial cells), as well as access requirements to microfabrication or bioanalytic facilities. Table 1 summarizes these approaches, highlighting for each technique the capacity, ability to control the microenvironment by supplying nutrients and 
removing byproducts, as well as advantages (+) and shortcomings (-) in recovering cells and expertise requirements.

\section{Probing Single Cells}

Multiple methods to probe single cell physiology exist, operating either in steady state or dynamic fashion. Each method has its distinct resolving capabilities and targets specific cell characteristics, such as its size, mass, and volume, as well as specific organelles or metabolites. Several excellent reviews have been published on the topic [10, 201-203], including recent ones on biomechanics, microanalytical separations and genomics [38, 201, 204], - topics that will not be reviewed herein.

On the contrary, our focus in this section is on methods that directly or indirectly probe the metabolic-state, or energy flow of single cells. Depending on their nature, the techniques are divided into non-destructive ones that permit dynamic analysis, namely label-free and fluorescence mediated microanalysis. We will also briefly discuss non-dynamic techniques, namely mass spectrometry and nuclear magnetic resonance. Key applications in single cell physiology and metabolic analysis will be discussed separately for each technique.

\subsection{Label Free Microanalysis}

Single cell microanalysis techniques will be reviewed in this section, namely techniques that can probe single cell physiology without the need of cell staining. Cell proliferation, mass, volume and chemometric content are the typical pieces of information that can be extracted from single cells with such strategies, and will be reviewed separately. 


\subsubsection{Proliferation}

In proliferation studies, cell growth in terms of number of individuals and their size is investigated, both of which with direct links to cell cycle and metabolic state. The most common instrument used to this end is conventional microscopy; however, more advanced, label-free, holographic approaches are becoming increasingly popular [205]. With the advent of advanced microfluidic architectures, proliferation studies have been revolutionized, and it is now possible to track parameters of multiple individual cells for many generations and under controlled chemostatic conditions $[70,80]$. Such recent developments involve the long-term and dynamic analysis of cell size and size homeostasis, as well as the relationship of these characteristics between mother and offspring cells (Fig. 8a) [206]. Single cell lifespan analysis was recently reported, linking cell age to specific phenotypic variations [131]; in this study, a microfluidic dissection device enabled single cell tracking with no cell-crowding due to the continuous removal of the newborn cells by flow (Fig. 5c). 1D confinement structures have also been extensively employed to track lineages of single cells [95], as well as their response to chemical perturbations, such as antibiotics [94]. It is also worth adding that portable cell-phone compatible microscopy platforms have been recently demonstrated, enabling important single-cell physiology and motility investigations [207, 208].

\subsubsection{Single Cell Volume and Mass}

The mass and volume are two physical characteristics also directly linked to cell cycle and metabolic state. Their importance has been recently recognized and several strategies for their measurement have been developed to this end.

Volume: Volume measurements can be imaging or impedance (resistance) based. An advanced imaging approach is the Reflection Interference Contrast (RIC) method, where angled white- 
light illumination gives rise to interference fringes; the number of which is directly proportional to the height of the cell [209]. In an alternative imaging approach, Bottier et al. employed 'negative staining', namely the addition of a fluorescent, non-permeable dye in the buffer surrounding the cells, followed by substantially simpler image analysis [210]. Impedance based methods are also very popular, such as the commercial Coulter technique, where cells decrease the electrical conductivity of an aperture as they transit in front of it. The conductivity decrease has an amplitude directly dependent on the cell volume [211].

The Coulter instrument was recently integrated with a temperature stabilized chemostat to enable 'continuous' population-scale measurements; the authors reported volume measurements of both yeast and mammalian cells for more than 3 hours of continuous growth [212]. Microfluidic approaches have also been reported. In one approach, microfluidic traps were integrated with the electrode-based volume sensor, enabling the monitoring of real-time volume changes of single cells for several minutes [213]. In another embodiment, Riordon et al. integrated the electrodes with a pneumatic valve in order to engineer the sensitivity of the volume sensor; by pressurizing the valve, the buffer volume in the vicinity of the electrodes is modified, in turn modulating accordingly the sensor dynamic range and sensitivity [214].

Mass: In one of the earliest attempts for accurate mass determination of a single - hydrated cell, the Manalis group developed the 'suspended micro-channel resonator'. In this approach, a microfluidic channel is engraved in a vacuum suspended microcantilever; as a cell flows through the microchannel, the mass of the microcantilever and its resonant frequency are modified [215]. Thus, by detecting changes in the microcantilever's resonance frequency, the 'buoyant' mass of a single cell can be accurately determined with the extraordinary sensitivity of 20-30 fg [216]. Recently, the same group integrated a single cell trap (section 2.2.4) for long-term 
immobilization and measurements of the single cell mass variation under chemometric conditions [217]. More recently, MEMS resonant sensors have been developed, on top of which adherent cells are deposited for continuous mass monitoring [218]. In this embodiment, due to the resonator being in a hydrated state, the reported mass resolution is lower, on the order of $1 \mathrm{pg}$ [219].

Interferometric optical techniques are also possible to infer mass information at the single cell level [220]. The operation principle is based on the optical phase delay experienced by light transmitted through a cell, which is proportional to the mass density of the cell. While initial attempts focused on the sensing of the refractive index of single cells [221], more recently, direct imaging techniques, such as the 'spatial light interference microscopy (SLIM)', have emerged [222]. These are label-free and non-invasive and, contrary to the aforementioned mechanical methods, they can perform rapid and sensitive mass measurements of individual cells even within populations [223].

\subsubsection{Microspectroscopic Chemical Analysis}

Microspectroscopy is a type of chemical analysis, realized by exciting the cell with a specific form of radiation, and analyzing the spectral response. Various such methods exist, categorized by the type of employed radiation, while imaging can also be achieved by spectral analysis at different (sub-cellular) locations. Common microspectroscopy methods for cell-physiology studies, such as Raman, infra-red and microbeam spectroscopy, will be reviewed separately in the following paragraphs.

Raman: In Raman microspectroscopy, laser light illuminates and scatters from a single cell at a different wavelength. This spectral shift depends on the vibrational frequencies of the intracellular molecules, which are distinct for specific chemical bonds. In this way, the 
intracellular content, such as proteins, fatty acids, and nucleic acids, can be analyzed (Fig. 8b) [6]. Raman techniques emerged more recently in cell biology [224]. By addressing related technical challenges [225], Raman analysis became possible not only on dehydrated [226], but also on hydrated [227] cells (Fig. 8c).

One of the unique characteristics of Raman microanalysis is its compatibility with optical tweezers (section 2.3.2). This is frequently referred to as Laser Tweezers Raman Spectroscopy (LTRS) and is based on the use of a single laser beam that both traps and excites the target cell [228]. This has enabled unique bioprocessing investigations, such as ethanol and lipid biosynthesis $[229,230]$. However, care needs to be taken to avoid cell photodamage, especially for prolonged single cell studies; the use of a near-IR excitation laser has been shown to only partially address this [231]. Metabolic analysis at the single cell level can also be performed by isotopic labeling, whereby incorporation of heavy isotopes shifts the Raman bands of the molecular bonds involved in the label incorporation [232].

Resonant Raman: In this microspectroscopy embodiment, the laser excitation wavelength is chosen to overlap with the absorption bands of fluorescent molecules inside the sample. In this way, the 'resonance' Raman effect is achieved, which greatly enhances the signal levels of the target by at least $10^{3}-10^{4}$ times. Typical examples involve the use of a UV excitation laser to detect the resonant Raman spectra of amino or nucleic acids [233, 234]. Due to the presence of autofluorescent compounds/pigments, resonance Raman has been particularly useful in the biochemical and metabolic studies of photosynthetic microorganisms [235]. Recently, the dynamics of cytochrome $c$ under physiological and stress conditions were studied by resonance Raman, revealing its role in cell apoptosis [236]. Due to its enhanced signal levels, resonance Raman greatly enhances the measurement's temporal resolution and minimizes photodamage; 
however, photobleaching of the involved fluorescent molecules can occur, eventually leading to signal degradation [174].

Surface Enhanced Raman (SERS): SERS is an alternative way to enhance the Raman efficiency and signal levels. In SERS, the cells are placed on either a rough, or a periodically structured metal surface [237]. The latter amplifies the local electromagnetic field; in turn, increasing signal sensitivity by a factor of up to $10^{15}$ [238]. However, SERS is strongly dependent on the distance of the metal surface to the target, with the enhancement levels decaying considerably even within $10 \mathrm{~nm}$. This can be addressed by appropriate metal layer chemical functionalization (section 2.2.4), which enables the simultaneous cell capture and SERS analysis [239]. Metallic nanoparticles may also be used, which upon internalization enable intracellular SERS microspectroscopy [240, 241]. Tip-enhanced Raman spectroscopy is also based on the same principle, with the tip itself acting as the local optical amplifier, and overall enabling Raman images of very high spatial resolution (down to $10 \mathrm{~nm}$ ) [242].

Coherent Raman: Coherent anti-Stokes Raman scattering (CARS) and Stimulated Raman Scattering (SRS) are two popular forms of coherent Raman microspectroscopy of single cells. In CARS, the sample is illuminated with two short-pulse (fs) laser beams instead of a single continuous wave like in spontaneous Raman. The frequency difference of the two excitation lasers needs to be equal to the vibrational frequency of the target bond, thus mapping specific chemical entities, such as lipids or proteins [243]. As a result, in comparison to spontaneous Raman, a significantly enhanced signal is obtained by more than 2 orders of magnitude [244]. CARS is a non-linear optical process (similar to two-photon absorption), hence exhibiting enhanced sectioning capabilities and making it ideal for 3D biological imaging. However, CARS 
is mostly applicable for imaging abundant intracellular species, as its signal strength rolls off rather quickly at low target analyte concentrations.

In CARS imaging, the background noise contribution from non-resonant chemical species is usually high, resulting in reduced chemical contrast. This has been addressed by implementing phase sensitive detection in Stimulated Raman Scattering (SRS) [245]. As a result, multiwavelength, rapid imaging of high resolution and specificity is possible, such as the biochemical and metabolic analysis of photosynthetic microorganisms (Fig. 8d) [246], and the internalization kinetics of small molecules [247].

Both CARS and SRS are highly promising in single cell chemical imaging due to their label-free nature, enhanced specificity, and sectioning ability. This is particularly pertinent in lipid imaging and spectroscopy at the single cell level. Such intracellular compartments are both abundant and exhibit a strong $\mathrm{C}-\mathrm{H}$ vibration mode at $2850 \mathrm{~cm}^{-1}$, making them readily detected with coherent Raman techniques with unsurpassed temporal resolution and chemical contrast. As a result, the areas of fundamental lipid biology and metabolism have experienced rapid growth due to the advent of such imaging platforms $[248,249]$. Both CARS and SRS however, require complex optical set-ups, while the long term effects of the employed intense laser pulses on the cell physiology and integrity remain to be identified [250-252].

Infrared (IR) microspectroscopy: In this embodiment, the IR absorption spectrum of an individual cell is captured to directly identify the structure and function of intracellular macromolecules $[253,254]$. The challenge in this strategy is primarily the signal saturation due to the strong IR absorption of water, which can be addressed by employing dehydrated samples [255]. Alternatively, ATR (attenuated-total-reflection) approaches can be employed to confine the excitation close to the substrate-medium interface, thus avoiding the water absorption, but 
also likely exciting a partial volume of the cell [256]. A third successful approach to avoid water absorption is the use of tailored designed chambers that minimize the media thickness, such as low-thickness [257], or open access microfluidics [258].

Due to the employment of longer excitation wavelengths, IR microscopy exhibits a larger (diffraction limited) excitation area compared to Raman. Despite this, the IR absorption spectra of isolated cells can still be measured, as in the successful determination of metabolite (EtOH) formation dynamics [259] and DNA conformation [260] in isolated cells. The use of solid immersion optical elements can increase the resolution down to 2-3 $\mu \mathrm{m}$ [261]. True superesolution IR imaging can be achieved by coupling IR to an Atomic Force Microscope probe, a strategy that has been shown to successfully detect triglycerides in dried cells with a 100 nm spatial resolution [262].

$X$-rays: Many types of X-ray microspectroscopy techniques for single cell elemental turn-over analysis exist, either in fluorescence or transmission mode [263]. The X-ray fluorescence microprobe is one of the first approaches in biology, well suited for the measurement of the concentration, location and turn-over rates of specific inorganic elements (Fig. 8e) [264]. A major application of this approach in the context of metabolism is the measurement of trace metal cycling at the single cell level for environmental applications [265, 266]. Soft X-ray microspectroscopy is a more recent technique, based on high-brightness synchrotron light sources and commonly operating in transmission mode (STXM) [267, 268]. 3D tomographic imaging is also possible in STXM by simply rotating the sample at discrete angles [269] (Fig. 8f). Overall, X-ray microspectroscopic imaging is ideal for structural imaging due to its $3 \mathrm{D}$ and $\mathrm{nm}$ resolution; long-term dynamic imaging is more challenging however because radiation dose can be damaging [270]. 


\subsubsection{Electrochemical Analysis}

Electrochemical methods are ideally suited for the analysis of the extracellular environment and the influence of cell secretion and cell-to-cell communication. To a similar note, microelectrophoretic approaches can also be applied to single cell analysis, as recently reviewed elsewhere [201]. Electrochemical methods are very attractive due to their low-capital investment requirements and microfluidic compatibility [203, 271-273]. Herein, our focus will be on single cell respiration, since oxygen - a common electron acceptor in metabolism - is rather electroactive and thus readily detectable. In the early attempts, scanning electrochemical microscopy (SECM) was employed, where a tip scanned over the cells and measured current modulations due to localized oxygen concentration variations [274]. While SECM has enabled very important findings, it was recently argued that the readings' accuracy is limited due to the cell's topography and associated challenges in maintaining the exact same scanning path during long-term measurements [275]. This challenge can be conveniently addressed by integrating the sensing electrodes with microfluidic control of the cell position, an approach that has recently enabled the precise quantification of respiration kinetics in single photosynthetic bacteria [276, 277].

\subsection{Fluorescence Mediated Microanalysis}

In this section, we will review fluorescent methods for registering metabolic activity and bioenergetics of single cells. This has been an established field for a many decades now, and numerous strategies and toolkits exist $-\mathrm{a}$ significant number of which are commercially available. Many excellent resources exist on this topic, such as the J. R. Lakowicz textbook for a complete background on fluorescence [278], as well as a few recent reviews on single cell 
fluorescent imaging and spectroscopy [279-281]. Detailing all available methods is beyond the scope of this review; our aim instead is to highlight key available methods (section 3.2.1) and related contrast agents (section 3.2.2) of practical use in investigating energy flow and metabolism at the single cell level.

\subsubsection{Methods}

Fluorescent single cell methods are generally divided into cytometry, microscopy, and their modifications, such as Fluorescence Correlated Spectroscopy (FCS) and Fluorescent Recovery After Photobleaching (FRAP). These are briefly discussed below.

Cytometry: In cytometry - also described earlier in the context of single cell manipulation (section 2.1.1) - the cells flow in front of one or more laser beams and their scattering or fluorescent properties are detected by opposing detectors. Alternative embodiments include the Laser Scanning (LSC) and Imaging cytometry, both of which are also commercially available. In $L S C$, the laser excitation is scanned over cells deposited on slides or membranes, and thus is not limited to studies involving only cells in solution as in conventional flow-cytometry [282, 283]. Imaging Cytometry refers to a wide range of techniques of high-throughput cell microscopy [284]. In the most common embodiment, cells are deposited on a slide and imaged at the single cell level using basic or advanced microscopy modalities [285]. More recently, microfluidic image cytometry (MIC) was reported, where cells are contained in discrete microfluidic chambers and undergo growth and long-term imaging cytometry for high-content screening $[286,287]$. 
Microscopy: The most common modality of fluorescent microscopy is the epi-fluorescent microscope using a laser (coherent) or a lamp (incoherent) excitation source [288]. To enhance the imaging contrast and enable 3D optical sectioning, techniques such as the confocal (laser scanning [289] or spin-disk [290]), and multi-photon [291] imaging, as well as light-sheet microscopy [292, 293] are currently available. Substantial accomplishments in superesolution microscopy have been recently reported, with even $10 \mathrm{~nm}$ resolution being possible [294]. The most common and commercially available strategies involve the Structured Illumination Microscopy (SIM), with a reported resolution of about 100-150 nm [295], and Stimulated Emission Depletion Microscopy (STED) with a $30 \mathrm{~nm}$ resolution limit [296]. 30-50 nm optical resolution can also be achieved by modulating the emission of single molecules, either stochastically, such as Stochastic Optical Reconstruction Microscopy (STORM) [297], and Photoactivated Localization Microscopy (PALM) [298], or, as more recently, deterministically using polarization modulation techniques [299].

Fluorescence Lifetime Imaging (FLIM): In FLIM, the image contrast is derived by the fluorophore excited-state lifetime at each pixel, rather than its intensity. Generally, there are two FLIM types, one operating in the frequency domain (frequency modulated illumination and detection) [300] and one that operates in the time domain by counting photons using fast lasers and detectors [301]. FLIM is a unique imaging modality, because it enables fluorophore discrimination based on their conformation and their local chemical microenvironment, both of which directly affect their excited state lifetime [302]. A common challenge in FLIM is the low photon budget at the pixel of each image, which however has been recently overcome by processing the image using the phasor analysis method [303]. As a result, FLIM has found many applications in metabolic imaging, especially by discriminating free and protein bound NADH 
(short and long lifetime respectively). This has in essence revolutionized in-vivo metabolic imaging applications, such as the discrimination of proliferative stem cell in living tissue [304].

Fluorescence Correlated Spectroscopy (FCS): In FCS, a laser beam illuminates part of the cell and the intracellular fluorescence is continuously monitored. The latter exhibits fluctuations which decipher intracellular molecular dynamics, such as the concentration and diffusion constant of fluorescent proteins [305]. Fluorescent Recovery After Photobleaching (FRAP) is a similar technique, where a location of the cell is continuously illuminated until bleached; subsequently, the dynamics of fluorescence recovery is monitored; namely, the diffusion in the observation volume of fresh, fluorescent molecules [306]. Similar to FCS, FRAP provides information about the diffusion and binding kinetics of fluorescent proteins.

\subsubsection{Contrast Agents}

Contrary to the aforementioned label-free techniques, in fluorescence, chromophores need to be implemented that absorb light at a specific wavelength and remit at a different one. Such molecules or probes that are crucial in exploring the physiology or metabolic state of single cells will be discussed in this section, including fluorescent proteins, enzymes and biosensors.

Fluorescent Proteins (FP): Since the advent of the green FP (GFP) cloned from the jellyfish Aequorea victoria [307], FPs have arguably become the workhorse contrast agent in modern bioimaging applications [308]. These genetically encoded chromophores exhibit now a wide variety of emission wavelengths (Fig. 9a), as well as enhanced photostability and brightness [309]. FPs are commonly used as reporters of other non-fluorescent proteins. This is achieved by fusing them to the protein of interest through a short peptide linker, which in turn is realized by cloning the FP sequence in a continuous open reading frame of the gene of interest [310]. FPs 
have found numerous single cell applications. One example involves the long-term single cell imaging of expression of genes linked to metabolic regulation. These investigations have been pioneering in elucidating metabolic gene regulation under perturbations [83], as well as the nature of stochastic transitions in metabolic networks, such as the 'all or non' behavior reported for the lactose [311], or galactose utilization [312]. FP fusions can also be used to tag specific intracellular organelles [313]; a few recent examples of this type specific to metabolism involve the high-throughput imaging of mitochondrion network size scaling during proliferation, [314] and the role of triacylglycerol enzymes in lipid droplet biosynthesis [315].

Physiological Fluorophores: Fluorescent (non-genetically encoded) probes capable of accumulating in specific intracellular organelles belong to this category [279]. There is a wide variety of such probes, each targeting a specific intracellular moiety. One of the earliest examples of this class is the stain of nucleic acids, such as the Hoechst or propidium iodide dyes $[24,316]$, with the latter being selectively internalized upon apoptosis, thus also functioning as a fitness indicator. Specific organelles may also be targeted, such the mitochondrion, [317] or the cell membrane [318], the latter also functioning as a vesicle-mediated internalization pathway indicator. Another important class of physiological fluorophores in bioprocessing are lipophilic dyes that selectively partition within lipid droplets [319], enabling thus the direct visualization of lipid droplet metabolism and strain selection [320].

Biosensors: These are a special class of probes that their optical properties are altered depending on variations of the local microenvironment [321]. Calcium sensors [322] belong to this category, as well as membrane potential [323] and hydrogen ion sensors [324]. The latter are ideal as metabolic activity indicators, operating on the simple principle that $\mathrm{pH}$ homeostasis cannot be maintained at low ATP production [325]. Such pH sensors were very recently 
employed to reveal subpopulations of distinct metabolic profile in isogenic cultures [21]. Other types of biosensors also exist, such as membrane potential and FRET ones; the interested reader is re-directed to recent reviews on the topic [29, 323].

Respiration activity is another important metabolic indicator, which can be optically detected, in addition to the previously discussed electrochemical methods (section 3.1.4). For the optical readout of respiration, specific phosphorescent sensors need to be employed. These, upon collision, transfer non-radiatively their energy to molecular oxygen and their intensity decreases [278]. Optical oxygen sensing has been applied both to microfluidic cultures [326], but also at the single cell level trapped in microwells [327, 328] (Fig. 9b). Indirect respiration detection is also possible, involving sensors such as the Redox Sensor Green dye [329]. Their operation is based on the active electron transport system during respiration, which reduces the sensing moiety and modifies its emission spectrum [330]. There are also many types of genetically encoded biosensors capable of detecting a variety of intracellular entities such as hydrogen peroxide [331] and calcium [332]. These do not need to undergo cell internalization in order to operate, thus substantially simplifying their use. Such sensors have recently found many applications in detecting intracellular concentrations of specific metabolites. In these, the metabolites react with transcriptional activators, initiating the expression of fluorescent proteins. Such recent biosensor examples involve the dynamic monitoring of amino acid production in the industrially relevant strain C. glutamicum (Fig. 9c) [333, 334].

Enzyme activity: Biosensors also exist for assaying enzyme activity [335]. Specific to single cell analysis, non-fluorescent and cell-permeable substrates can be employed, which are then enzymatically converted into a fluorescent one. Two very basic examples are Calcein-AM [336] and Alamar Blue (resazurin) [337] that become fluorescent or lose their emission respectively 
upon enzymatic reaction. Fluorescent substrates adhered on the cell membranes have also been reported; these have been useful in selecting protease variants by FACS: desired variants cleaved the fluorescent unit, thus exhibiting no fluorescence and enabling FACS sorting [338].

With the advent of microfluidics, it has been recently possible to assay secreted metabolites in intact cells, as well as lyse cells and quantify their intracellular metabolite content. Regarding metabolite secretion, single enzyme studies in pneumatically isolated microfluidic chambers, [152] or population screening in microfluidic droplets have been reported [20]. In the latter report, the use of microfluidic droplets enabled the concentration of the secreted metabolite, with the impressive ability to identify 1 desired variant in a population of $10^{4}$ cells (Fig. 9d) [20]. A coupled enzymatic assay was employed based on the indicator Amplex UltraRed, which converts into a fluorescent compound in the presence of horseradish peroxidase and hydrogen peroxide $\left(\mathrm{H}_{2} \mathrm{O}_{2}\right)$, the latter being the product of oxidase mediated metabolite oxidation [339]. In regards to assaying lysed cells, single cells were trapped in a microfluidic chamber, and underwent several washing steps and eventually lysis. Lysate targets were then surface immobilized and quantified by a sandwich ELISA assay [340].

\subsection{Mass Spectrometry Methods (MS)}

Specific to metabolomics, much recent technological advancement has enabled operation at the single cell level. These technologies have been reviewed recently in many excellent reports [341343], so we will only summarize key recent findings and remaining challenges. In regards to challenges, one is the tremendous variability of metabolites, as well as their rapid turnover rates-even at the single cell level [10]. As recently reviewed by Heinemann et al., several strategies have been developed to address this, including chemical separations prior to detection, 
microfluidic cell handling and nanophotonic signal enhancement [343, 344]. The use of complementary detection methods in addition to mass-spectrometry has also gathered considerable excitement. One such example is the selective analysis of either the cytoplasm or of the intracellular compartments by combining nano-electrospray ionization (ESI-MS) with video microscopy [345] as illustrated in Fig. 11a-b.

Achieving high-throughput and statistically significant single cell data is another challenge in metabolomics. To address this, one approach developed by the Zenobi group is microarrays for mass spectrometry (MAMS). Contrary to microwell approaches (section 2.2.1), MAMS contain an array of hydrophilic spots on a hydrophobic surface, thereby isolating one or a few cells in a spatially organized matrix [346]. This approach enabled the group to characterize metabolic population variability in yeast using MALDI MS [347]. In an alternative approach, to achieve ultra-high throughput, the Nolan and Tarren groups developed the mass cytometer, whereby single cells are stained with isotopically labelled antibodies and subsequently analyzed in an ICP-MS [39]. The technique - termed CyTOF - enabled the simultaneous detection of 34 different parameters. CyTOF was primarily used for immunophenotyping of single cells. Given appropriate antibodies, the technique is also ideal for high-throughput single cell metabolomics. Single cell MS imaging is also possible, by analyzing specific locations of the cell sequentially. The most traditional approach has been the MALDI-MS, which exhibits a spatial resolution of approximately $1 \mu \mathrm{m}$ [348]. By using an ion instead of a laser beam, the more recent 'secondary ion mass spectrometric' imaging (SIMS) exceeds the spatial resolution limit of MALDI-MS by more than one order of magnitude [232, 349] (Fig. 10c). However, compared to MALDI, SIMS exhibits lower chemical specificity, which can be addressed by supplying the targets with 
isotopically labelled nutrients. Sampling at different times also enables the turn-over determination of specific macromolecules [350, 351] (Fig. 10d-f).

Finally, it is worth noting that single-cell proteomics is also currently pursued with MS; however, little progress has been achieved to this end, primarily due to the small number of proteins in individual cells, and the inability to amplify such analytes as commonly done in gene studies and sequencing. LTQ-Orbitrap MS is the most promising strategy to address this; however, extremely efficient sample handling needs to be perfected towards this task [341].

\subsection{Nuclear Magnetic Resonance Methods (NMR)}

Single cell metabolomics with NMR is still a field at its infancy, exhibiting still insufficient detection limits. However, both the information content that can be extracted with NMR and the fact that it is a non-invasive technique are unique and very attractive features [352]. NMR of very large cells such as oocytes [353] and neurons [354] has been possible, albeit at an incomplete metabolome coverage. Recent progress however in designing novel microcoil probes, [355] and the integration of NMR with microfluidics. Both are very promising approaches that have so far enabled further decrease of the observation volume and enhanced the sensitivity down to the nmol regime [356].

\section{Conclusions}

Single cell analyses, such as imaging and sequencing, have been of crucial importance in modern life sciences and particular systems biology. More recently, such analyses were applied to metabolic investigations and engineering, enabling unique observations, such as the discovery of subpopulations with distinct metabolic profile [20, 21, 357], and the quantification of metabolic 
variability in populations [347]. The importance of such findings spans not only systems biology, environmental microbiology and the biomedical field, but also industrial applications of synthetic biology, where such phenotypic variations are known to negatively impact productivity [330, 358]. Further insight in this domain will clearly lead to better understanding of environmental challenges, as well as identifying novel therapeutic and metabolic engineering approaches.

With this review, our aim is to outline presently available techniques for isolating and probing the bioenergetics and metabolic potential of individual cells. While each individual category (manipulation and probing) are promising by themselves, their co-integration is likely to enable a deeper insight in to the origins and effects of cellular metabolic heterogeneity. This is evident by the recent discoveries enabled by the fusion of droplet microfluidics with advanced fluorescence techniques [20], and that of single cell surface patterning with mass spectrometry [347]. Emerging computational and microanalytical techniques will also play a critical role; the latter involving 'omics' analysis of microbial cells with enhanced coverage and 'correlative microscopy' [359] by fusing MS with superesolution microscopy [360] for both analyzing metabolic network function and structure.

\section{Acknowledgments}

AEV gratefully acknowledges funding support from the Pacific Northwest National Laboratory (Linus Pauling LDRD project ID: PN12005/2406) and GS from the DOE, Genomic Sciences program and ARPA-E REMOTE program. We also wish to - in advance - apologize to those investigators and colleagues whose work was not cited herein due to space limitations. 


\section{Figure Captions}

Figure 1: From many down to the single cell; (a) An industrial scale fermenter with an approximate height of a few meters (credit U.S. Department of Energy). (b) A bioreactor growing algae; the vertical dimension of the instrument is a few $\mathrm{cm}$ containing approximately $10^{12}$ cells (credit U.S. Department of Energy). (c) A budding Yarrowia Lipolytica yeast, with the daughter cell exhibiting an approximate $2 \mu \mathrm{m}$ diameter. (c) Schematic representations of the 2D, 1D and OD confinement types discussed in this review.

Figure 2: Flow-through single cell analysis; In (a), the schematic of a conventional single cell flow cytometer is illustrated (Reprinted by permission from Macmillan Publishers Ltd: Nature Reviews Microbiology [361], Copyright (2008). (b) Loading of single cells in droplets at a microfluidic T-junction; the black arrows point to the individual cell in the droplet (reproduced from [362] with permission from The Royal Society of Chemistry). (c) Single hybridoma cell encapsulation in arrested droplets (reprinted by permission from Macmillan Publishers Ltd: Nature Protocols [55], Copyright (2013).

Figure 3: Confinement in 3D microcavities; (a) A schematic of the fabrication and seeding of PDMS microwell arrays; the procedure involves pouring and curing the prepolymer on to a patterned master, and subsequently peeling off and placing the microwells in a Petri dish; finally, the cell suspension is introduced and allowed to sediment onto the microwells, and excess cells from the top surface are rinsed (reprinted from [66]; Copyright (2005) American Chemical Society). (b) An SEM image of single trapped Jurkat T cells in an array of cell retainers etched in $\mathrm{SiO}_{2}$; scale bar is $20 \mu \mathrm{m}$ (reproduced from [68] with permission from The Royal Society of Chemistry). (c) Mammalian cells trapped in microwell arrays at the bottom of a microfluidic 
channel; the microwells are the circular structures and the microfluidic channel walls are denoted by the straight lines (reproduced from [78] with permission from The Royal Society of Chemistry).

Figure 4: $2 D$ and $1 D$ Confinement; A zoomed-in view of the Tesla microchemostat (a), illustrating the 'diode loop' with the trapping (grey) and loading (black) regions; in (b) the shallow trapping region of Tesla microchemostat is shown, where cells are confined in 2D; the scale bar is $20 \mu \mathrm{m}$ [82] (Copyright (C) 2005 EMBO and Nature Publishing Group). (c) A bioreactor with a shallow circular 2D growth area placed inside a deeper supply channel; note the radially arranged channels that enable nutrient supply and waste removal (reproduced from [89] with permission from The Royal Society of Chemistry). (d) 1D bacterial growth in 1D patterned agarose (lower) in contrast to agarose pads were bacterial crowding takes place (upper); reproduced from [97] with permission from The Royal Society of Chemistry.

Figure 5: OD Confinement; (a) Microfluidic single cell trapping (left), where cells are trapped at the stagnation point and kept there immobilized by flow driven hydrostatic pressure (denoted by white arrows). A bright field image of an individual trapped Jurkat T-cell (right); adapted from [103]; Copyright (2003) American Chemical Society. In (b), a single cell trapping array is illustrated (left, scale bar is $500 \mu \mathrm{m}$ ); a higher resolution image of the trapping array (middle), along with an individual trapped cell (right); reproduced from [104] with permission from The Royal Society of Chemistry. (c) Monolithic PDMS pads for trapping yeast cells, while releasing the daughter cells under the continuous flow of media (adapted from [131]). (d) A schematic diagram of a microfluidic 'lateral percolation' trap; the operation principle is based on the geometric relationship between paths 1 and 2 . When the trap is empty, the resistance of path 1 is 
lower until a cell occupies, after which subsequent cells will follow the bypass loop (adapted from [110]; Copyright (2007) National Academy of Sciences, U.S.A.).

Figure 6: Dynamic Confinement 1; (a) A schematic representation of a pneumatically isolated microcavity; cell trapping occurs by compressing the flow channel by the two control channels (reprinted by permission from Macmillan Publishers Ltd: Nature [152], Copyright (2006). (b) A fluorescently labelled E. coli trapped inside a submicrofluidic indentation; release takes place by increasing the flow rate (reproduced from [106] with permission from The Royal Society of Chemistry). (c) A single cell hydrodynamic trap by generating microeddies around a solid cylinder at low frequency oscillations of flow (reproduced from [158]; Copyright (2006) American Chemical Society). (d) A stagnation point generated at the junction of two perpendicular microchannels; active feedback flow control ensures the stabilization of the stagnation point and the immobilization of a single cell therein (reprinted with permission from [160]; Copyright (2010), AIP Publishing LLC).

Figure 7: Dynamic Confinement 2; Schematic representation of single cell trapping by OT (a) and a 'dual beam trap' (b). In (c), radiation pressure forces enable selective release of microwell loaded cells (reproduced from [178]; Copyright (2007) American Chemical Society). (d) DEP trapping of a Pollen grain in an eight electrode electric field cage (reprinted from [189] Copyright (1993), with permission from Elsevier). In (e), the cell loading and retrieval is illustrated for the magnetic microrafts (reprinted with permission from [198]; Copyright (2011), AIP Publishing LLC).

Figure 8: Label-free microanalysis; (a) Single cell proliferation in a microchemostat (reprinted from [206]). In (b), the Raman spectrum of a bacterium is plotted, including the major bands 
attributions (reprinted from [226]; Copyright (2000) American Chemical Society). (c) Raman images of yeast at different wavenumber regions, marking specific intracellular molecular fractions (adapted from [363]; Copyright @ 2005 John Wiley \& Sons, Ltd). In (d) a multiplex SRS image of single algal cells, depicting photosynthetic pigments (red), lipids (green) and protein (blue); (adapted from [246]; Copyright (2000) American Chemical Society). (e) Elemental maps from X-ray emission of the marine species $D$. norvegica using a nuclear microprobe at a $5 \mu \mathrm{m}$ spatial resolution (adapted from [264]). (f) A budding yeast cell imaged by soft X-ray tomography, where different colors represent different organelles (reproduced with permission from [269]).

Figure 9: Fluorescence mediated microanalysis: (a) Chromophore classes found in fluorescent proteins and their respective emission bands (reprinted by permission from Macmillan Publishers Ltd: Nature Chemical Biology [309], Copyright (2014). (b) A phosphorescent oxygen sensor at the bottom of a microwell plate containing two cells (reprinted from [328], Copyright (2009), with permission from Elsevier). (c) Population heterogeneity in the production of L-valine, revealed by an FP-fused genetically encoded biosensor (reproduced from [333]). (d) Microfluidic high-throughput screening platform of secreted metabolites in microfluidic droplets; reprinted by permission from Macmillan Publishers Ltd: Nature Biotechnology [20], Copyright (2014).

Figure 10: Mass spectrometry: Sequential clips illustrating the metabolic analysis of single cells using nano-electrospray ionization (ESI-MS); in this instance, video microscopy enables the selective analysis of the cytoplasm (a) or individual granules (b); reprinted from [345]; Copyright $@ 2008$ John Wiley \& Sons, Ltd. (c) Schematic illustrating the NanoSIMS imaging of a single cell: the secondary ion beam rasters over the sample removes material to be analyzed by MS. Quantitative raster NanoSIMS images of the R. palustris bacterium, illustrating the 
distribution of ${ }^{12} \mathrm{C}^{-}$(d) and ${ }^{13} \mathrm{C}^{-}(\mathrm{e})$; image (f) illustrates the ${ }^{13} \mathrm{C}^{-}$enrichment at one pole of the cells (reproduced from [351]).

Table 1: A table summarizing single cell manipulation strategies as discussed in section 2. The 'method' column describes the associated technique, including the characteristic 'type' (ie. flow through, dynamic, permanent), its ability to 'recover' cells, its 'capacity' (in number of cells), the 'expertise' requirements (+, -: low, high), its ability to control the chemical 'microenvironment', its 'surface noise' properties (arising from non-specific surface adhesion and leading to optical or chemical noise), and finally the related 'section' and 'references'. 


\section{References}

1. Hildebrand, E.M., Infectivity of the fire-blight organism. Phytopath., 1937. 27: p. 850852.

2. Mortimer, R.K. and J.R. Johnston, Life span of individual yeast cells. Nature, 1959. 183(4677): p. 1751-1752.

3. Zelle, M.R., A simple single-cell technique for genetic studies of bacteria. Journal of Bacteriology, 1951. 61(3): p. 345-349.

4. Hildebrand, E.M., Techniques for the isolation of single microorganisms II. Botanical Review, 1950. 16(4): p. 181-207.

5. Andersson, H. and A. van den Berg, Microfluidic devices for cellomics: a review. Sensors and Actuators B-Chemical, 2003. 92(3): p. 315-325.

6. Brehm-Stecher, B.F. and E.A. Johnson, Single-cell microbiology: Tools, technologies, and applications. Microbiology and Molecular Biology Reviews, 2004. 68(3): p. 538-+.

7. Nilsson, J., et al., Review of cell and particle trapping in microfluidic systems. Analytica Chimica Acta, 2009. 649(2): p. 141-157.

8. Schmid, A., et al., Chemical and biological single cell analysis. Current Opinion in Biotechnology, 2010. 21(1): p. 12-20.

9. Lecault, V., et al., Microfluidic single cell analysis: from promise to practice. Current Opinion in Chemical Biology, 2012. 16(3-4): p. 381-390.

10. Zenobi, R., Single-Cell Metabolomics: Analytical and Biological Perspectives. Science, 2013. 342(6163): p. 1201-+.

11. Huang, N.-T., et al., Recent advancements in optofluidics-based single-cell analysis: optical on-chip cellular manipulation, treatment, and property detection. Lab on a Chip, 2014. 14(7): p. 1230-1245.

12. Grünberger, A., W. Wiechert, and D. Kohlheyer, Single-cell microfluidics: opportunity for bioprocess development. Current Opinion in Biotechnology, 2014. 29: p. 15-23.

13. Avesar, J., T.B. Arye, and S. Levenberg, Frontier microfluidic techniques for short and long-term single cell analysis. Lab on a Chip, 2014. 14: p. 2161-2167.

14. Mu, X., et al., Microfluidics for Manipulating Cells. Small, 2013. 9(1): p. 9-21.

15. Bennett, M.R. and J. Hasty, Microfluidic devices for measuring gene network dynamics in single cells. Nature Reviews Genetics, 2009. 10(9): p. 628-638. 
16. Xia, Y.N. and G.M. Whitesides, Soft lithography. Annual Review of Materials Science, 1998. 28: p. 153-184.

17. Quake, S.R. and A. Scherer, From micro- to nanofabrication with soft materials. Science, 2000. 290(5496): p. 1536-1540.

18. Weibel, D.B., W.R. DiLuzio, and G.M. Whitesides, Microfabrication meets microbiology. Nature Reviews Microbiology, 2007. 5(3): p. 209-218.

19. Hong, J., J.B. Edel, and A.J. deMello, Micro- and nanofluidic systems for highthroughput biological screening. Drug Discovery Today, 2009. 14(3-4): p. 134-146.

20. Wang, B.L., et al., Microfluidic high-throughput culturing of single cells for selection based on extracellular metabolite production or consumption. Nature biotechnology, 2014. 32(5): p. 473-8.

21. van Heerden, J.H., et al., Lost in Transition: Start-Up of Glycolysis Yields Subpopulations of Nongrowing Cells. Science, 2014. 343(6174): p. 987-+.

22. Croslandtaylor, P.J., A device for counting small particles suspended in a fluid through a tube. Nature, 1953. 171(4340): p. 37-38.

23. Kamentsk.La, M.R. Melamed, and H. Derman, Spectrophotometer - New instrument for ultrarapid cell analysis. Science, 1965. 150(3696): p. 630-\&.

24. Shapiro, H.M., Practical Flow Cytometry. 2003, Hoboken, New Jersey: John Wiley \& Sons Inc.

25. Taylor, L.D., High Content Screening. Methods in Molecular Biology, ed. L.D. Taylor, J.R. Haskins, and K.A. Giuliano. 2007, Totowa, New Jersey 07512: Humana Press Inc.

26. Ozbudak, E.M., et al., Regulation of noise in the expression of a single gene. Nature Genetics, 2002. 31(1): p. 69-73.

27. Blake, W.J., et al., Noise in eukaryotic gene expression. Nature, 2003. 422(6932): p. 633637.

28. Newman, J.R.S., et al., Single-cell proteomic analysis of S-cerevisiae reveals the architecture of biological noise. Nature, 2006. 441(7095): p. 840-846.

29. Tracy, B.P., S.M. Gaida, and E.T. Papoutsakis, Flow cytometry for bacteria: enabling metabolic engineering, synthetic biology and the elucidation of complex phenotypes. Current Opinion in Biotechnology, 2010. 21(1): p. 85-99.

30. Fu, A.Y., et al., A microfabricated fluorescence-activated cell sorter. Nature Biotechnology, 1999. 17(11): p. 1109-1111.

31. Huh, D., et al., Microfluidics for flow cytometric analysis of cells and particles. Physiological Measurement, 2005. 26(3): p. R73-R98. 
32. Schrum, D.P., et al., Microchip flow cytometry using electrokinetic focusing. Analytical Chemistry, 1999. 71(19): p. 4173-4177.

33. Wolff, A., et al., Integrating advanced functionality in a microfabricated high-throughput fluorescent-activated cell sorter. Lab on a Chip, 2003. 3(1): p. 22-27.

34. Gawad, S., et al., Dielectric spectroscopy in a micromachined flow cytometer: theoretical and practical considerations. Lab on a Chip, 2004. 4(3): p. 241-251.

35. Lau, A.Y., L.P. Lee, and J.W. Chan, An integrated optofluidic platform for Ramanactivated cell sorting. Lab on a Chip, 2008. 8(7): p. 1116-1120.

36. Sohn, L.L., et al., Capacitance cytometry: Measuring biological cells one by one. Proceedings of the National Academy of Sciences of the United States of America, 2000. 97(20): p. 10687-10690.

37. Shaker, M., et al., An impedance-based flow microcytometer for single cell morphology discrimination. Lab on a Chip, 2014: p. DOI: 10.1039/c4lc00221k.

38. Zheng, Y., et al., Recent advances in microfluidic techniques for single-cell biophysical characterization. Lab on a Chip, 2013. 13(13): p. 2464-2483.

39. Bendall, S.C., et al., Single-Cell Mass Cytometry of Differential Immune and Drug Responses Across a Human Hematopoietic Continuum. Science, 2011. 332(6030): p. 687-696.

40. Thorsen, T., et al., Dynamic pattern formation in a vesicle-generating microfluidic device. Physical Review Letters, 2001. 86(18): p. 4163-4166.

41. Garstecki, P., et al., Formation of droplets and bubbles in a microfluidic T-junction scaling and mechanism of break-up. Lab on a Chip, 2006. 6(3): p. 437-446.

42. Teh, S.-Y., et al., Droplet microfluidics. Lab on a Chip, 2008. 8(2): p. 198-220.

43. Nisisako, T., T. Torii, and T. Higuchi, Droplet formation in a microchannel network. Lab on a Chip, 2002. 2(1): p. 24-26.

44. Tice, J.D., et al., Formation of droplets and mixing in multiphase microfluidics at low values of the Reynolds and the capillary numbers. Langmuir, 2003. 19(22): p. 9127-9133.

45. Song, H., D.L. Chen, and R.F. Ismagilov, Reactions in droplets in microflulidic channels. Angewandte Chemie-International Edition, 2006. 45(44): p. 7336-7356.

46. Song, H. and R.F. Ismagilov, Millisecond kinetics on a microfluidic chip using nanoliters of reagents. Journal of the American Chemical Society, 2003. 125(47): p. 14613-14619.

47. Niu, X., et al., A microdroplet dilutor for high-throughput screening. Nature Chemistry, 2011. 3(6): p. 437-442.

48. Kintses, B., et al., Microfluidic droplets: new integrated workflows for biological experiments. Current Opinion in Chemical Biology, 2010. 14(5): p. 548-555. 
49. He, M.Y., et al., Selective encapsulation of single cells and subcellular organelles into picoliter- and femtoliter-volume droplets. Analytical Chemistry, 2005. 77(6): p. 15391544.

50. Edd, J.F., et al., Controlled encapsulation of single-cells into monodisperse picolitre drops. Lab on a Chip, 2008. 8(8): p. 1262-1264.

51. Koester, S., et al., Drop-based microfluidic devices for encapsulation of single cells. Lab on a Chip, 2008. 8(7): p. 1110-1115.

52. Huebner, A., et al., Quantitative detection of protein expression in single cells using droplet microfluidics. Chemical Communications, 2007(12): p. 1218-1220.

53. Eun, Y.-J., et al., Encapsulating Bacteria in Agarose Microparticles Using Microfluidics for High-Throughput Cell Analysis and Isolation. Acs Chemical Biology, 2011. 6(3): p. 260-266.

54. Guo, M.T., et al., Droplet microfluidics for high-throughput biological assays. Lab on a Chip, 2012. 12(12): p. 2146-2155.

55. Mazutis, L., et al., Single-cell analysis and sorting using droplet-based microfluidics. Nature Protocols, 2013. 8(5): p. 870-891.

56. Leung, K., et al., A programmable droplet-based microfluidic device applied to multiparameter analysis of single microbes and microbial communities. Proceedings of the National Academy of Sciences of the United States of America, 2012. 109(20): p. 7665-7670.

57. Novak, R., et al., Single-Cell Multiplex Gene Detection and Sequencing with Microfluidically Generated Agarose Emulsions. Angewandte Chemie-International Edition, 2011. 50(2): p. 390-395.

58. Zeng, Y., et al., High-Performance Single Cell Genetic Analysis Using Microfluidic Emulsion Generator Arrays. Analytical Chemistry, 2010. 82(8): p. 3183-3190.

59. Baret, J.-C., et al., Fluorescence-activated droplet sorting (FADS): efficient microfluidic cell sorting based on enzymatic activity. Lab on a Chip, 2009. 9(13): p. 1850-1858.

60. Aharoni, A., et al., High-throughput screening of enzyme libraries: Thiolactonases evolved by fluorescence-activated sorting of single cells in emulsion compartments. Chemistry \& Biology, 2005. 12(12): p. 1281-1289.

61. Brouzes, E., et al., Droplet microfluidic technology for single-cell high-throughput screening. Proceedings of the National Academy of Sciences of the United States of America, 2009. 106(34): p. 14195-14200.

62. Agresti, J.J., et al., Ultrahigh-throughput screening in drop-based microfluidics for directed evolution. Proceedings of the National Academy of Sciences of the United States of America, 2010. 107(9): p. 4004-4009. 
63. Lagus, T.P. and J.F. Edd, A review of the theory, methods and recent applications of high-throughput single-cell droplet microfluidics. Journal of Physics D-Applied Physics, 2013. 46(11).

64. Charnley, M., et al., Integration column: microwell arrays for mammalian cell culture. Integrative Biology, 2009. 1(11-12): p. 625-634.

65. Parce, J.W., et al., Detection of cell-affecting agents with a silicon biosensor. Science, 1989. 246(4927): p. 243-247.

66. Rettig, J.R. and A. Folch, Large-scale single-cell trapping and imaging using microwell arrays. Analytical Chemistry, 2005. 77(17): p. 5628-5634.

67. Sasuga, Y., et al., Single-Cell Chemical Lysis Method for Analyses of Intracellular Molecules Using an Array of Picoliter-Scale Microwells. Analytical Chemistry, 2008. 80(23): p. 9141-9149.

68. Deutsch, M., et al., A novel miniature cell retainer for correlative high-content analysis of individual untethered non-adherent cells. Lab on a Chip, 2006. 6(8): p. 995-1000.

69. Lutolf, M.P., et al., Perturbation of single hematopoietic stem cell fates in artificial niches. Integrative Biology, 2009. 1(1): p. 59-69.

70. Lecault, V., et al., High-throughput analysis of single hematopoietic stem cell proliferation in microfluidic cell culture arrays. Nature Methods, 2011. 8(7): p. 581-U93.

71. Ochsner, M., et al., Micro-well arrays for 3D shape control and high resolution analysis of single cells. Lab on a Chip, 2007. 7(8): p. 1074-1077.

72. Gobaa, S., et al., Artificial niche microarrays for probing single stem cell fate in high throughput. Nature Methods, 2011. 8(11): p. 949-955.

73. Zurgil, N., et al., Donut-shaped chambers for analysis of biochemical processes at the cellular and subcellular levels. Lab on a Chip, 2014. 14(DOI: 10.1039/C3LC51426A ): p. 2226-2239

74. Wood, D.K., et al., Single cell trapping and DNA damage analysis using microwell arrays. Proceedings of the National Academy of Sciences of the United States of America, 2010. 107(22): p. 10008-10013.

75. Ryley, J. and O.M. Pereira-Smith, Microfluidics device for single cell gene expression analysis in Saccharomyces cerevisiae. Yeast, 2006. 23(14-15): p. 1065-1073.

76. Balagadde, F.K., et al., Long-term monitoring of bacteria undergoing programmed population control in a microchemostat. Science, 2005. 309(5731): p. 137-140.

77. Liu, K., et al., Cell culture chip using low-shear mass transport. Langmuir, 2008. 24(11): p. 5955-5960.

78. Khademhosseini, A., et al., Molded polyethylene glycol microstructures for capturing cells within microfluidic channels. Lab on a Chip, 2004. 4(5): p. 425-430. 
79. Cosson, S. and M.P. Lutolf, Hydrogel microfluidics for the patterning of pluripotent stem cells. Scientific Reports, 2014. 4.

80. Groisman, A., et al., A microfluidic chemostat for experiments with bacterial and yeast cells. Nature Methods, 2005. 2(9): p. 685-689.

81. Connell, J.L., et al., Probing Prokaryotic Social Behaviors with Bacterial "Lobster Traps". Mbio, 2010. 1(4).

82. Cookson, S., et al., Monitoring dynamics of single-cell gene expression over multiple cell cycles. Molecular Systems Biology, 2005. 1.

83. Bennett, M.R., et al., Metabolic gene regulation in a dynamically changing environment. Nature, 2008. 454(7208): p. 1119-1122.

84. Lee, P.J., et al., A microfluidic system for dynamic yeast cell imaging. Biotechniques, 2008. 44(1): p. 91-95.

85. Ullman, G., et al., High-throughput gene expression analysis at the level of single proteins using a microfluidic turbidostat and automated cell tracking. Philosophical Transactions of the Royal Society B-Biological Sciences, 2013. 368(1611).

86. Binder, D., et al., Light-responsive control of bacterial gene expression: Precise triggering of the lac promoter activity using photocaged IPTG Integrative Biology, 2014(DOI: 10.1039/C4IB00027G ).

87. Denervaud, N., et al., A chemostat array enables the spatio-temporal analysis of the yeast proteome. Proceedings of the National Academy of Sciences of the United States of America, 2013. 110(39): p. 15842-15847.

88. Mather, W., et al., Streaming Instability in Growing Cell Populations. Physical Review Letters, 2010. 104(20).

89. Gruenberger, A., et al., A disposable picolitre bioreactor for cultivation and investigation of industrially relevant bacteria on the single cell level. Lab on a Chip, 2012. 12(11): p. 2060-2068.

90. Long, T. and R.M. Ford, Enhanced Transverse Migration of Bacteria by Chemotaxis in a Porous T-Sensor. Environmental Science \& Technology, 2009. 43(5): p. 1546-1552.

91. Zhang, C., et al., Effects of Pore-Scale Heterogeneity and Transverse Mixing on Bacterial Growth in Porous Media. Environmental Science \& Technology, 2010. 44(8): p. 3085-3092.

92. Vasdekis, A.E., et al., Solvent immersion imprint lithography. Lab on a chip, 2014. 14(12): p. 2072-80.

93. Carlson, R.H., et al., Self-sorting of white blood cells in a lattice. Physical Review Letters, 1997. 79(11): p. 2149-2152. 
94. Balaban, N.Q., et al., Bacterial persistence as a phenotypic switch. Science, 2004. 305(5690): p. 1622-1625.

95. Rowat, A.C., et al., Tracking lineages of single cells in lines using a microfluidic device. Proceedings of the National Academy of Sciences of the United States of America, 2009. 106(43): p. 18149-18154.

96. Wang, P., et al., Robust Growth of Escherichia coil. Current Biology, 2010. 20(12): p. 1099-1103.

97. Moffitt, J.R., J.B. Lee, and P. Cluzel, The single-cell chemostat: an agarose-based, microfluidic device for high-throughput, single-cell studies of bacteria and bacterial communities. Lab on a Chip, 2012. 12(8): p. 1487-1494.

98. Norman, T.M., et al., Memory and modularity in cell-fate decision making. Nature, 2013. 503(7477): p. 481-+.

99. Long, Z., et al., Microfluidic chemostat for measuring single cell dynamics in bacteria. Lab on a Chip, 2013. 13(5): p. 947-954.

100. Moolman, M.C., et al., Electron beam fabrication of a microfluidic device for studying submicron-scale bacteria. Journal of Nanobiotechnology, 2013. 11.

101. He, B., L. Tan, and F. Regnier, Microfabricated filters for microfluidic analytical systems. Analytical Chemistry, 1999. 71(7): p. 1464-1468.

102. de Mello, A.J. and N. Beard, Dealing with 'real' samples: sample pre-treatment in microfluidic systems. Lab on a Chip, 2003. 3(1): p. 11N-19N.

103. Wheeler, A.R., et al., Microfluidic device for single-cell analysis. Analytical Chemistry, 2003. 75(14): p. 3581-3586.

104. Di Carlo, D., L.Y. Wu, and L.P. Lee, Dynamic single cell culture array. Lab on a Chip, 2006. 6(11): p. 1445-1449.

105. Eyer, K., et al., A microchamber array for single cell isolation and analysis of intracellular biomolecules. Lab on a Chip, 2012. 12(4): p. 765-772.

106. Vasdekis, A.E., Single microbe trap and release in sub-microfluidics. Rsc Advances, 2013. 3(18): p. 6343-6346.

107. Kim, M.-C., et al., Programmed trapping of individual bacteria using micrometre-size sieves. Lab on a Chip, 2011. 11(6): p. 1089-1095.

108. Probst, C., et al., Polydimethylsiloxane (PDMS) Sub-Micron Traps for Single-Cell Analysis of Bacteria. Micromachines, 2013. 4(4): p. 357-369.

109. Huberts, D.H.E.W., et al., Construction and use of a microfluidic dissection platform for long-term imaging of cellular processes in budding yeast. Nature Protocols, 2013. 8(6): p. 1019-1027. 
110. Tan, W.-H. and S. Takeuchi, A trap-and-release integrated microfluidic system for dynamic microarray applications. Proceedings of the National Academy of Sciences of the United States of America, 2007. 104(4): p. 1146-1151.

111. Kobel, S.A., et al., Automated analysis of single stem cells in microfluidic traps. Lab on a Chip, 2012. 12(16): p. 2843-2849.

112. Bell, L., et al., A microfluidic device for the hydrodynamic immobilisation of living fission yeast cells for super-resolution imaging. Sensors and Actuators B-Chemical, 2014. 192: p. 36-41.

113. Hong, S., Q. Pan, and L.P. Lee, Single-cell level co-culture platform for intercellular communication. Integrative Biology, 2012. 4(4): p. 374-380.

114. Schmitz, C.H.J., et al., Dropspots: a picoliter array in a microfluidic device. Lab on a Chip, 2009. 9(1): p. 44-49.

115. Khorshidi, M.A., et al., Automated analysis of dynamic behavior of single cells in picoliter droplets. Lab on a Chip, 2014. 14(5): p. 931-937.

116. Young, J.W., et al., Measuring single-cell gene expression dynamics in bacteria using fluorescence time-lapse microscopy. Nature Protocols, 2012. 7(1): p. 80-88.

117. Rosenfeld, N., et al., Gene regulation at the single-cell level. Science, 2005. 307(5717): p. 1962-1965.

118. Kaufmann, B.B., et al., Heritable stochastic switching revealed by single-cell genealogy. Plos Biology, 2007. 5(9): p. 1973-1980.

119. Hunt, N.C. and L.M. Grover, Cell encapsulation using biopolymer gels for regenerative medicine. Biotechnology Letters, 2010. 32(6): p. 733-742.

120. Hubbell, J.A., Biomaterials in tissue engineering. Bio-Technology, 1995. 13(6): p. 565576.

121. Heo, J., et al., A microfluidic bioreactor based on hydrogel-entrapped E. coli: Cell viability, lysis, and intracellular enzyme reactions. Analytical Chemistry, 2003. 75(1): p. 22-26.

122. Braschler, T., et al., Gentle cell trapping and release on a microfluidic chip by in situ alginate hydrogel formation. Lab on a Chip, 2005. 5(5): p. 553-559.

123. Falconnet, D., et al., High-throughput tracking of single yeast cells in a microfluidic imaging matrix. Lab on a Chip, 2011. 11(3): p. 466-473.

124. Robert, L., et al., Pre-dispositions and epigenetic inheritance in the Escherichia coli lactose operon bistable switch. Molecular Systems Biology, 2010. 6.

125. Kang, A., et al., Cell encapsulation via microtechnologies. Biomaterials, 2014. 35(9): p. 2651-63. 
126. Warrick, J.W., et al., High-content adhesion assay to address limited cell samples. Integrative Biology, 2013. 5(4): p. 720-727.

127. Tuson, H.H. and D.B. Weibel, Bacteria-surface interactions. Soft Matter, 2013. 9(17): p. 4368-4380.

128. Guillemot, G., et al., Evaluating the adhesion force between Saccharomyces cerevisiae yeast cells and polystyrene from shear-flow induced detachment experiments. Chemical Engineering Research \& Design, 2007. 85(A6): p. 800-807.

129. Helmstetter, C.E., Description of a baby machine for Saccharomyces-Cervisiae. New Biologist, 1991. 3(11): p. 1089-1096.

130. Helmstetter, C.E., et al., Improved Bacterial Baby Machine - Applications to Escherichia-Coli K12. Journal of Bacteriology, 1992. 174(11): p. 3445-3449.

131. Lee, S.S., et al., Whole lifespan microscopic observation of budding yeast aging through a microfluidic dissection platform. Proceedings of the National Academy of Sciences of the United States of America, 2012. 109(13): p. 4916-4920.

132. Taniguchi, Y., et al., Quantifying E-coli Proteome and Transcriptome with SingleMolecule Sensitivity in Single Cells. Science, 2010. 329(5991): p. 533-538.

133. Vasdekis, A.E., et al., Precision Intracellular Delivery Based on Optofluidic Polymersome Rupture. Acs Nano, 2012. 6(9): p. 7850-7857.

134. Stojkovic, G. and P. Znidarsic-Plazl, Immobilization of Yeast Cells Within Microchannels of Different Materials. Acta Chimica Slovenica, 2010. 57(1): p. 144-149.

135. Kuhn, P., et al., A facile protocol for the immobilisation of vesicles, virus particles, bacteria, and yeast cells. Integrative Biology, 2012. 4(12): p. 1550-1555.

136. Mrksich, M. and G.M. Whitesides, Patterning self-assembled monolayers using microcontact printing - a new technology for biosensors. Trends in Biotechnology, 1995. 13(6): p. 228-235.

137. Whitesides, G.M., et al., Soft lithography in biology and biochemistry. Annual Review of Biomedical Engineering, 2001. 3: p. 335-373.

138. Singhvi, R., et al., Engineering cell shape and function. Science, 1994. 264(5159): p. 696-698.

139. Jiang, X.Y., et al., Electrochemical desorption of self-assembled monolayers noninvasively releases patterned cells from geometrical confinements. Journal of the American Chemical Society, 2003. 125(9): p. 2366-2367.

140. Ward, J.H., R. Bashir, and N.A. Peppas, Micropatterning of biomedical polymer surfaces by novel UV polymerization techniques. Journal of Biomedical Materials Research, 2001. 56(3): p. 351-360. 
141. Jang, K., et al., Surface modification by 2-methacryloyloxyethyl phosphorylcholine coupled to a photolabile linker for cell micropatterning. Biomaterials, 2009. 30(7): p. 1413-1420.

142. Sun, J., et al., Technique of Surface Modification of a Cell-Adhesion-Resistant Hydrogel by a Cell-Adhesion-Available Inorganic Microarray. Biomacromolecules, 2008. 9(10): p. 2569-2572.

143. Bearinger, J.P., et al., Chemical tethering of motile bacteria to silicon surfaces. Biotechniques, 2009. 46(3): p. 209-+.

144. Jang, K., et al., Single-cell attachment and culture method using a photochemical reaction in a closed microfluidic system. Biomicrofluidics, 2010. 4(3).

145. Douglas, E.S., et al., DNA-barcode directed capture and electrochemical metabolic analysis of single mammalian cells on a microelectrode array. Lab on a Chip, 2009. 9(14): p. 2010-2015.

146. Mettetal, J.T., et al., The frequency dependence of osmo-adaptation in Saccharomyces cerevisiae. Science, 2008. 319(5862): p. 482-484.

147. Siegal-Gaskins, D. and S. Crosson, Tightly regulated and heritable division control in single bacterial cells. Biophysical Journal, 2008. 95(4): p. 2063-2072.

148. Didar, T.F. and M. Tabrizian, Adhesion based detection, sorting and enrichment of cells in microfluidic Lab-on-Chip devices. Lab on a Chip, 2010. 10(22): p. 3043-3053.

149. Otto, K. and M. Hermansson, Inactivation of ompX causes increased interactions of type 1 fimbriated Escherichia coli with abiotic surfaces. Journal of Bacteriology, 2004. 186(1): p. 226-234.

150. Unger, M.A., et al., Monolithic microfabricated valves and pumps by multilayer soft lithography. Science, 2000. 288(5463): p. 113-116.

151. Kim, H., S. Lee, and J. Kim, Hydrodynamic trap-and-release of single particles using dual-function elastomeric valves: design, fabrication, and characterization. Microfluidics and Nanofluidics, 2012. 13(5): p. 835-844.

152. Cai, L., N. Friedman, and X.S. Xie, Stochastic protein expression in individual cells at the single molecule level. Nature, 2006. 440(7082): p. 358-362.

153. Weinstein, J.A., et al., High-Throughput Sequencing of the Zebrafish Antibody Repertoire. Science, 2009. 324(5928): p. 807-810.

154. Fan, H.C., et al., Whole-genome molecular haplotyping of single cells. Nature Biotechnology, 2011. 29(1): p. 51-+.

155. Streets, A.M., et al., Microfluidic single-cell whole-transcriptome sequencing. Proceedings of the National Academy of Sciences of the United States of America, 2014. 111(19): p. 7048-53. 
156. Karimi, A., S. Yazdi, and A.M. Ardekani, Hydrodynamic mechanisms of cell and particle trapping in microfluidics. Biomicrofluidics, 2013. 7(2).

157. Perkins, T.T., D.E. Smith, and S. Chu, Single polymer dynamics in an elongational flow. Science, 1997. 276(5321): p. 2016-2021.

158. Lutz, B.R., J. Chen, and D.T. Schwartz, Hydrodynamic tweezers: 1. Noncontact trapping of single cells using steady streaming microeddies. Analytical Chemistry, 2006. 78(15): p. 5429-5435.

159. Lieu, V.H., T.A. House, and D.T. Schwartz, Hydrodynamic Tweezers: Impact of Design Geometry on Flow and Microparticle Trapping. Analytical Chemistry, 2012. 84(4): p. 1963-1968.

160. Tanyeri, M., E.M. Johnson-Chavarria, and C.M. Schroeder, Hydrodynamic trap for single particles and cells. Applied Physics Letters, 2010. 96(22).

161. Tanyeri, M., et al., A microfluidic-based hydrodynamic trap: design and implementation. Lab on a Chip, 2011. 11(10): p. 1786-1794.

162. Baker, N.V., Segregation and sedimentation of red blood cells in ultrasonic standing waves. Nature, 1972. 239(5372): p. 398-\&.

163. Friend, J. and L.Y. Yeo, Microscale acoustofluidics: Microfluidics driven via acoustics and ultrasonics. Reviews of Modern Physics, 2011. 83(2): p. 647-704.

164. Bazou, D., L.A. Kuznetsova, and W.T. Coakley, Physical enviroment of 2-D animal cell aggregates formed in a short pathlength ultrasound standing wave trap. Ultrasound in Medicine and Biology, 2005. 31(3): p. 423-430.

165. Evander, M., et al., Noninvasive acoustic cell trapping in a microfluidic perfusion system for online bioassays. Analytical Chemistry, 2007. 79(7): p. 2984-2991.

166. Ding, X., et al., On-chip manipulation of single microparticles, cells, and organisms using surface acoustic waves. Proceedings of the National Academy of Sciences of the United States of America, 2012. 109(28): p. 11105-11109.

167. Ashkin, A. and J.M. Dziedzic, Optical trapping and manipulation of viruses and bacteria. Science, 1987. 235(4795): p. 1517-1520.

168. Ashkin, A., et al., Observation of a single beam gradient force optical trap for dielectric particles. Optics Letters, 1986. 11(5): p. 288-290.

169. Neuman, K.C., et al., Characterization of photodamage to Escherichia coli in optical traps. Biophysical Journal, 1999. 77(5): p. 2856-2863.

170. Eriksson, E., et al., Optical manipulation and microfluidics for studies of single cell dynamics. Journal of Optics a-Pure and Applied Optics, 2007. 9(8): p. S113-S121. 
171. Werner, M., et al., Microfluidic array cytometer based on refractive optical tweezers for parallel trapping, imaging and sorting of individual cells. Lab on a Chip, 2011. 11(14): p. 2432-2439.

172. Probst, C., et al., Microfluidic growth chambers with optical tweezers for full spatial single-cell control and analysis of evolving microbes. Journal of Microbiological Methods, 2013. 95(3): p. 470-476.

173. Arai, F., et al., On chip single-cell separation and immobilization using optical tweezers and thermosensitive hydrogel. Lab on a Chip, 2005. 5(12): p. 1399-1403.

174. Chen, D., S.-s. Huang, and Y.-q. Li, Real-time detection of kinetic germination and heterogeneity of single Bacillus spores by laser tweezers Raman spectroscopy. Analytical Chemistry, 2006. 78(19): p. 6936-6941.

175. Ashkin, A., Acceleration and trapping of particles by radiation pressure. Physical Review Letters, 1970. 24(4): p. 156-\&.

176. Ashok, P.C. and K. Dholakia, Optical trapping for analytical biotechnology. Current Opinion in Biotechnology, 2012. 23(1): p. 16-21.

177. Lincoln, B., et al., Reconfigurable microfluidic integration of a dual-beam laser trap with biomedical applications. Biomedical Microdevices, 2007. 9(5): p. 703-710.

178. Kovac, J.R. and J. Voldman, Intuitive, image-based cell sorting using optofluidic cell sorting. Analytical Chemistry, 2007. 79(24): p. 9321-9330.

179. Ahluwalia, B.S., et al., Optical trapping and propulsion of red blood cells on waveguide surfaces. Optics Express, 2010. 18(20): p. 21053-21061.

180. Yang, A.H.J., et al., Optical manipulation of nanoparticles and biomolecules in subwavelength slot waveguides. Nature, 2009. 457(7225): p. 71-75.

181. Hughes, M.P., Strategies for dielectrophoretic separation in laboratory-on-a-chip systems. Electrophoresis, 2002. 23(16): p. 2569-2582.

182. Chiou, P.Y., A.T. Ohta, and M.C. Wu, Massively parallel manipulation of single cells and microparticles using optical images. Nature, 2005. 436(7049): p. 370-372.

183. Huang, K.-W., et al., Microfluidic integrated optoelectronic tweezers for single-cell preparation and analysis. Lab on a Chip, 2013. 13(18): p. 3721-3727.

184. Jeorrett, A.H., et al., Optoelectronic tweezers system for single cell manipulation and fluorescence imaging of live immune cells. Optics Express, 2014. 22(2): p. 1372-1380.

185. Tamura, M., et al., Optical cell separation from three-dimensional environment in photodegradable hydrogels for pure culture techniques. Scientific Reports, 2014. 4.

186. Sun, T., J. Kovac, and J. Voldman, Image-Based Single-Cell Sorting via DualPhotopolymerized Microwell Arrays. Analytical Chemistry, 2014. 86(2): p. 977-981. 
187. Voldman, J., Electrical forces for microscale cell manipulation, in Annual Review of Biomedical Engineering. 2006. p. 425-454.

188. Khoshmanesh, K., et al., Dielectrophoretic platforms for bio-microfluidic systems. Biosensors \& Bioelectronics, 2011. 26(5): p. 1800-1814.

189. Schnelle, T., et al., 3-dimensional electric-field traps for manipulation of cells calculation and experimental verification. Biochimica Et Biophysica Acta, 1993. 1157(2): p. 127-140.

190. Hunt, T.P., D. Issadore, and R.M. Westervelt, Integrated circuit/microfluidic chip to programmably trap and move cells and droplets with dielectrophoresis. Lab on a Chip, 2008. 8(1): p. 81-87.

191. Thomas, R.S., H. Morgan, and N.G. Green, Negative DEP traps for single cell immobilisation. Lab on a Chip, 2009. 9(11): p. 1534-1540.

192. Manaresi, N., et al., A CMOS chip for individual cell manipulation and detection. Ieee Journal of Solid-State Circuits, 2003. 38(12): p. 2297-2305.

193. Zhu, Z., et al., Microfluidic single-cell cultivation chip with controllable immobilization and selective release of yeast cells. Lab on a Chip, 2012. 12(5): p. 906-915.

194. Seger, U., et al., Temperature measurements in microfluidic systems: Heat dissipation of negative dielectrophoresis barriers. Electrophoresis, 2005. 26(11): p. 2239-2246.

195. Dusny, C., et al., Isolated Microbial Single Cells and Resulting Micropopulations Grow Faster in Controlled Environments. Applied and Environmental Microbiology, 2012. 78(19): p. 7132-7136.

196. Ino, K., et al., Cell culture arrays using magnetic force-based cell patterning for dynamic single cell analysis. Lab on a Chip, 2008. 8(1): p. 134-142.

197. Winkleman, A., et al., A magnetic trap for living cells suspended in a paramagnetic buffer. Applied Physics Letters, 2004. 85(12): p. 2411-2413.

198. Gach, P.C., et al., Isolation and manipulation of living adherent cells by micromolded magnetic rafts. Biomicrofluidics, 2011. 5(3).

199. Petit, T., et al., Selective Trapping and Manipulation of Microscale Objects Using Mobile Microvortices. Nano Letters, 2012. 12(1): p. 156-160.

200. Ye, Z. and M. Sitti, Dynamic trapping and two-dimensional transport of swimming microorganisms using a rotating magnetic microrobot. Lab on a Chip, 2014. 14(13): p. 2177-2182.

201. Borland, L.M., et al., Chemical Analysis of Single Cells, in Annual Review of Analytical Chemistry. 2008. p. 191-227.

202. Galler, K., et al., Making a big thing of a small cell - recent advances in single cell analysis. Analyst, 2014. 139(6): p. 1237-1273. 
203. Trouillon, R., et al., Chemical Analysis of Single Cells. Analytical Chemistry, 2013. 85(2): p. 522-542.

204. Kalisky, T. and S.R. Quake, Single-cell genomics. Nature Methods, 2011. 8(4): p. 311314.

205. Cotte, Y., et al., Marker-free phase nanoscopy. Nature Photonics, 2013. 7(2): p. 113-117.

206. Nobs, J.-B. and S.J. Maerkl, Long-Term Single Cell Analysis of S. pombe on a Microfluidic Microchemostat Array. Plos One, 2014. 9(4).

207. Cui, X., et al., Lensless high-resolution on-chip optofluidic microscopes for Caenorhabditis elegans and cell imaging. Proceedings of the National Academy of Sciences of the United States of America, 2008. 105(31): p. 10670-10675.

208. Su, T.-W., L. Xue, and A. Ozcan, High-throughput lensfree 3D tracking of human sperms reveals rare statistics of helical trajectories. Proceedings of the National Academy of Sciences of the United States of America, 2012. 109(40): p. 16018-16022.

209. Strohmeier, R. and J. Bereiterhahn, Hydrostatic pressure in epidermal cells is dependent on Ca-mediated contractions. Journal of Cell Science, 1987. 88: p. 631-640.

210. Bottier, C., et al., Dynamic measurement of the height and volume of migrating cells by a novel fluorescence microscopy technique. Lab on a Chip, 2011. 11(22): p. 3855-3863.

211. Coulter, W.H., High speed automatic blood cell counter and cell size analyzer. Proc Natl Electron Conf 1956. 12: p. 1034-1040.

212. Bryan, A.K., et al., Continuous and Long-Term Volume Measurements with a Commercial Coulter Counter. Plos One, 2012. 7(1).

213. Hua, S.Z. and T. Pennell, A microfluidic chip for real-time studies of the volume of single cells. Lab on a Chip, 2009. 9(2): p. 251-256.

214. Riordon, J., M. Mirzaei, and M. Godin, Microfluidic cell volume sensor with tunable sensitivity. Lab on a Chip, 2012. 12(17): p. 3016-3019.

215. Godin, M., et al., Using buoyant mass to measure the growth of single cells. Nature Methods, 2010. 7(5): p. 387-U70.

216. Burg, T.P., et al., Weighing of biomolecules, single cells and single nanoparticles in fluid. Nature, 2007. 446(7139): p. 1066-1069.

217. Weng, Y., et al., Mass sensors with mechanical traps for weighing single cells in different fluids. Lab on a Chip, 2011. 11(24): p. 4174-4180.

218. Corbin, E.A., et al., Micro-patterning of mammalian cells on suspended MEMS resonant sensors for long-term growth measurements. Lab on a Chip, 2014. 14(8): p. 1401-1404. 
219. Park, K., et al., Measurement of adherent cell mass and growth. Proceedings of the National Academy of Sciences of the United States of America, 2010. 107(48): p. 2069120696.

220. Popescu, G., et al., New technologies for measuring single cell mass. Lab on a Chip, 2014. 14(4): p. 646-652.

221. Song, W.Z., et al., Refractive index measurement of single living cells using on-chip Fabry-Perot cavity. Applied Physics Letters, 2006. 89(20).

222. Wang, Z., et al., Spatial light interference microscopy (SLIM). Optics Express, 2011. 19(2): p. 1016-1026.

223. Mir, M., et al., Optical measurement of cycle-dependent cell growth. Proceedings of the National Academy of Sciences of the United States of America, 2011. 108(32): p. 1312413129.

224. Puppels, G.J., et al., Studying single living cells and chromosomes by confocal Raman microspectroscopy. Nature, 1990. 347(6290): p. 301-303.

225. Brauchle, E. and K. Schenke-Layland, Raman spectroscopy in biomedicine - noninvasive in vitro analysis of cells and extracellular matrix components in tissues. Biotechnology Journal, 2013. 8(3): p. 288-297.

226. Schuster, K.C., et al., Multidimensional information on the chemical composition of single bacterial cells by confocal Raman microspectroscopy. Analytical Chemistry, 2000. 72(22): p. 5529-5534.

227. Krafft, C., et al., Studies on stress-induced changes at the subcellular level by Raman microspectroscopic mapping. Analytical Chemistry, 2006. 78(13): p. 4424-4429.

228. Xie, C.G., D. Chen, and Y.Q. Li, Raman sorting and identification of single living microorganisms with optical tweezers. Optics Letters, 2005. 30(14): p. 1800-1802.

229. Peng, L., et al., Intracellular ethanol accumulation in yeast cells during aerobic fermentation: a Raman spectroscopic exploration. Letters in Applied Microbiology, 2010. 51(6): p. 632-638.

230. Wu, H., et al., In vivo lipidomics using single-cell Raman spectroscopy. Proceedings of the National Academy of Sciences of the United States of America, 2011. 108(9): p. 3809-3814.

231. Xie, C.G., et al., Study of dynamical process of heat denaturation in optically trapped single microorganisms by near-infrared Raman spectroscopy. Journal of Applied Physics, 2003. 94(9): p. 6138-6142.

232. Wagner, M., Single-Cell Ecophysiology of Microbes as Revealed by Raman Microspectroscopy or Secondary Ion Mass Spectrometry Imaging, in Annual Review of Microbiology. 2009. p. 411-429. 
233. Asher, S.A., UV resonance Raman studies of molecular-structure and dynamics; applications in physical and biophysical chemistry. Annual Review of Physical Chemistry, 1988. 39: p. 537-588.

234. Puppels, G.J., et al., Laser irradiation and Raman spectroscopy of single living cells and chromosomes - sample degradation occurs with $514.5 \mathrm{~nm}$ but not $660 \mathrm{~nm}$ laser light. Experimental Cell Research, 1991. 195(2): p. 361-367.

235. Li, M., et al., Rapid resonance Raman microspectroscopy to probe carbon dioxide fixation by single cells in microbial communities. Isme Journal, 2012. 6(4): p. 875-885.

236. Okada, M., et al., Label-free Raman observation of cytochrome $c$ dynamics during apoptosis. Proceedings of the National Academy of Sciences of the United States of America, 2012. 109(1): p. 28-32.

237. Camden, J.P., et al., Controlled Plasmonic Nanostructures for Surface-Enhanced Spectroscopy and Sensing. Accounts of Chemical Research, 2008. 41(12): p. 1653-1661.

238. Nie, S.M. and S.R. Emery, Probing single molecules and single nanoparticles by surfaceenhanced Raman scattering. Science, 1997. 275(5303): p. 1102-1106.

239. Liu, T.-Y., et al., Functionalized arrays of Raman-enhancing nanoparticles for capture and culture-free analysis of bacteria in human blood. Nature Communications, 2011. 2.

240. Yuan, H., et al., Plasmonic nanoprobes for intracellular sensing and imaging. Analytical and Bioanalytical Chemistry, 2013. 405(19): p. 6165-6180.

241. Vitol, E.A., et al., Nanoprobes for intracellular and single cell surface-enhanced Raman spectroscopy (SERS). Journal of Raman Spectroscopy, 2012. 43(7): p. 817-827.

242. Schmid, T., et al., Nanoscale Chemical Imaging Using Tip-Enhanced Raman Spectroscopy: A Critical Review. Angewandte Chemie-International Edition, 2013. 52(23): p. 5940-5954.

243. Cheng, J.X. and X.S. Xie, Coherent anti-Stokes Raman scattering microscopy: Instrumentation, theory, and applications. Journal of Physical Chemistry B, 2004. 108(3): p. 827-840.

244. Pezacki, J.P., et al., Chemical contrast for imaging living systems: molecular vibrations drive CARS microscopy. Nature Chemical Biology, 2011. 7(3): p. 137-145.

245. Freudiger, C.W., et al., Label-Free Biomedical Imaging with High Sensitivity by Stimulated Raman Scattering Microscopy. Science, 2008. 322(5909): p. 1857-1861.

246. Fu, D., et al., Quantitative Chemical Imaging with Multiplex Stimulated Raman Scattering Microscopy. Journal of the American Chemical Society, 2012. 134(8): p. 3623-3626. 
247. Fu, D., et al., Imaging the intracellular distribution of tyrosine kinase inhibitors in living cells with quantitative hyperspectral stimulated Raman scattering. Nature Chemistry, 2014. 6: p. 614-622.

248. Hellerer, T., et al., Monitoring of lipid storage in Caenorhabditis elegans using coherent anti-Stokes Raman scattering (CARS) microscopy. Proceedings of the National Academy of Sciences of the United States of America, 2007. 104(37): p. 14658-14663.

249. Nan, X.L., J.X. Cheng, and X.S. Xie, Vibrational imaging of lipid droplets in live fibroblast cells with coherent anti-Stokes Raman scattering microscopy. Journal of Lipid Research, 2003. 44(11): p. 2202-2208.

250. Petrov, G.I., et al., Comparison of coherent and spontaneous Raman microspectroscopies for noninvasive detection of single bacterial endospores. Proceedings of the National Academy of Sciences of the United States of America, 2007. 104(19): p. 7776-7779.

251. Yakovlev, V.V., Advanced instrumentation for non-linear Raman microscopy. Journal of Raman Spectroscopy, 2003. 34(12): p. 957-964.

252. Radulovic, M., et al., The emergence of lipid droplets in yeast: current status and experimental approaches. Current Genetics, 2013. 59(4): p. 231-242.

253. Quaroni, L. and T. Zlateva, Infrared spectromicroscopy of biochemistry in functional single cells. Analyst, 2011. 136(16): p. 3219-3232.

254. Kazarian, S.G. and K.L.A. Chan, ATR-FTIR spectroscopic imaging: recent advances and applications to biological systems. Analyst, 2013. 138(7): p. 1940-1951.

255. Romeo, M., et al., Infrared microspectroscopy of individual human cervical cancer (HeLa) cells. Biopolymers, 2004. 74(1-2): p. 168-171.

256. Kuimova, M.K., K.L.A. Chan, and S.G. Kazarian, Chemical Imaging of Live Cancer Cells in the Natural Aqueous Environment. Applied Spectroscopy, 2009. 63(2): p. 164171.

257. Nasse, M.J., et al., Demountable Liquid/Flow Cell for in Vivo Infrared Microspectroscopy of Biological Specimens. Applied Spectroscopy, 2009. 63(10): p. 1181-1186.

258. Holman, H.-Y.N., et al., Real-Time Chemical Imaging of Bacterial Activity in Biofilms Using Open-Channel Microfluidics and Synchrotron FTIR Spectromicroscopy. Analytical Chemistry, 2009. 81(20): p. 8564-8570.

259. Goff, K.L., L. Quaroni, and K.E. Wilson, Measurement of metabolite formation in single living cells of Chlamydomonas reinhardtii using synchrotron Fourier-Transform Infrared spectromicroscopy. Analyst, 2009. 134(11): p. 2216-2219.

260. Whelan, D.R., et al., Monitoring the reversible B to A-like transition of DNA in eukaryotic cells using Fourier transform infrared spectroscopy. Nucleic Acids Research, 2011. 39(13): p. 5439-5448. 
261. Chan, K.L.A. and S.G. Kazarian, New opportunities in micro- and macro-attenuated total reflection infrared spectroscopic imaging: Spatial resolution and sampling versatility. Applied Spectroscopy, 2003. 57(4): p. 381-389.

262. Deniset-Besseau, A., et al., Monitoring TriAcylGlycerols Accumulation by Atomic Force Microscopy Based Infrared Spectroscopy in Streptomyces Species for Biodiesel Applications. Journal of Physical Chemistry Letters, 2014. 5(4): p. 654-658.

263. Sakdinawat, A. and D. Attwood, Nanoscale X-ray imaging. Nature Photonics, 2010. 4(12): p. 840-848.

264. Gisselson, L.A., E. Graneli, and J. Pallon, Variation in cellular nutrient status within a population of Dinophysis norvegica (Dinophyceae) growing in situ: Single-cell elemental analysis by use of a nuclear microprobe. Limnology and Oceanography, 2001. 46(5): p. 1237-1242.

265. Twining, B.S., et al., Quantifying trace elements in individual aquatic protist cells with a synchrotron X-ray fluorescence microprobe. Analytical Chemistry, 2003. 75(15): p. 3806-3816.

266. Yun, W., et al., X-ray imaging and microspectroscopy of plants and fungi. Journal of Synchrotron Radiation, 1998. 5: p. 1390-1395.

267. Hitchcock, A.P., et al., Soft X-ray spectromicroscopy of biological and synthetic polymer systems. Journal of Electron Spectroscopy and Related Phenomena, 2005. 144: p. 259269.

268. Barinov, A., et al., Synchrotron-based photoelectron microscopy. Nuclear Instruments \& Methods in Physics Research Section a-Accelerators Spectrometers Detectors and Associated Equipment, 2009. 601(1-2): p. 195-202.

269. Parkinson, D.Y., et al., Quantitative 3-D imaging of eukaryotic cells using soft X-ray tomography. Journal of Structural Biology, 2008. 162(3): p. 380-386.

270. Beetz, T. and C. Jacobsen, Soft X-ray radiation-damage studies in PMMA using a cryoSTXM. Journal of Synchrotron Radiation, 2003. 10: p. 280-283.

271. Kim, D., et al., Electroanalytical Eavesdropping on Single Cell Communication. Analytical Chemistry, 2011. 83(19): p. 7242-7249.

272. Lama, R.D., et al., Ultrafast Detection and Quantification of Brain Signaling Molecules with Carbon Fiber Microelectrodes. Analytical Chemistry, 2012. 84(19): p. 8096-8101.

273. Nebel, M., et al., Microelectrochemical visualization of oxygen consumption of single living cells. Faraday Discussions, 2013. 164: p. 19-32.

274. Kaya, T., et al., Monitoring the cellular activity of a cultured single cell by scanning electrochemical microscopy (SECM). A comparison with fluorescence viability monitoring. Biosensors \& Bioelectronics, 2003. 18(11): p. 1379-1383. 
275. Nebel, M., et al., Visualization of Oxygen Consumption of Single Living Cells by Scanning Electrochemical Microscopy: The Influence of the Faradaic Tip Reaction. Angewandte Chemie-International Edition, 2013. 52(24): p. 6335-6338.

276. Koide, M., et al., An electrochemical device with microwells for determining the photosynthetic activity of a single cyanobacterium. Sensors and Actuators B-Chemical, 2011. 153(2): p. 474-478.

277. Koide, M., et al., Microfluidic Devices for Electrochemical Measurement of Photosynthetic Activity of Cyanobacteria Microcystis Cells. Analytical Sciences, 2012. 28(1): p. 69-72.

278. Lakowicz, J.R., Principles of Fluorescence Spectroscopy. 3rd ed. ed. 2006, New York: Springer Science.

279. Lichtman, J.W. and J.A. Conchello, Fluorescence microscopy. Nature Methods, 2005. 2(12): p. 910-919.

280. Ntziachristos, V., Fluorescence molecular imaging. Annual review of biomedical engineering, 2006. 8: p. 1-33.

281. Stender, A.S., et al., Single Cell Optical Imaging and Spectroscopy. Chemical Reviews, 2013. 113(4): p. 2469-2527.

282. Pozarowski, P., E. Holden, and Z. Darzynkiewicz, Laser scanning cytometry: principles and applications-an update. Methods in molecular biology (Clifton, N.J.), 2013. 931: p. $187-212$.

283. Pozarowski, P., E. Holden, and Z. Darzynkiewicz, Laser scanning cytometry: principles and applications. Methods in molecular biology (Clifton, N.J.), 2006. 319: p. 165-92.

284. Doudkine, A., et al., Nuclear texture measurements in image cytometry. Pathologica, 1995. 87(3): p. 286-99.

285. Chumnanpuen, P., et al., Lipid biosynthesis monitored at the single-cell level in Saccharomyces cerevisiae. Biotechnology Journal, 2012. 7(5): p. 594-601.

286. Kamei, K.-i., et al., Microfluidic image cytometry for quantitative single-cell profiling of human pluripotent stem cells in chemically defined conditions. Lab on a Chip, 2010. 10(9): p. 1113-1119.

287. Kim, M.J., et al., High-content screening of drug-induced cardiotoxicity using quantitative single cell imaging cytometry on microfluidic device. Lab on a Chip, 2011. 11(1): p. 104-114.

288. Webb, D.J. and C.M. Brown, Epi-fluorescence microscopy. Methods in molecular biology (Clifton, N.J.), 2013. 931: p. 29-59. 
289. White, J.G., W.B. Amos, and M. Fordham, An evaluation of confocal versus conventional imaging of biological structures by fluorescence light microscopy. Journal of Cell Biology, 1987. 105(1): p. 41-48.

290. Nakano, A., Spinning-disk confocal microscopy - A cutting-edge tool for imaging of membrane traffic. Cell Structure and Function, 2002. 27(5): p. 349-355.

291. Denk, W., J.H. Strickler, and W.W. Webb, 2-photon laser scanning fluorescence microscopy. Science, 1990. 248(4951): p. 73-76.

292. Keller, P.J., et al., Fast, high-contrast imaging of animal development with scanned light sheet-based structured-illumination microscopy. Nature Methods, 2010. 7(8): p. 637U55.

293. Verveer, P.J., et al., High-resolution three-dimensional imaging of large specimens with light sheet-based microscopy. Nature Methods, 2007. 4(4): p. 311-313.

294. Huang, B., M. Bates, and X. Zhuang, Super-Resolution Fluorescence Microscopy, in Annual Review of Biochemistry. 2009. p. 993-1016.

295. Gustafsson, M.G.L., Nonlinear structured-illumination microscopy: Wide-field fluorescence imaging with theoretically unlimited resolution. Proceedings of the National Academy of Sciences of the United States of America, 2005. 102(37): p. 13081-13086.

296. Willig, K.I., et al., STED microscopy reveals that synaptotagmin remains clustered after synaptic vesicle exocytosis. Nature, 2006. 440(7086): p. 935-939.

297. Rust, M.J., M. Bates, and X. Zhuang, Sub-diffraction-limit imaging by stochastic optical reconstruction microscopy (STORM). Nature Methods, 2006. 3(10): p. 793-795.

298. Shroff, H., et al., Live-cell photoactivated localization microscopy of nanoscale adhesion dynamics. Nature Methods, 2008. 5(5): p. 417-423.

299. Hafi, N., et al., Fluorescence nanoscopy by polarization modulation and polarization angle narrowing. Nature Methods, 2014. 11(5): p. 579-584.

300. Lakowicz, J.R., et al., Fluorescence lifetime imaging. Analytical Biochemistry, 1992. 202(2): p. 316-330.

301. Becker, W., et al., Fluorescence lifetime imaging by time-correlated single-photon counting. Microscopy Research and Technique, 2004. 63(1): p. 58-66.

302. Gratton, E., et al., Fluorescence lifetime imaging for the two-photon microscope: timedomain and frequency-domain methods. Journal of Biomedical Optics, 2003. 8(3): p. 381-390.

303. Digman, M.A., et al., The phasor approach to fluorescence lifetime imaging analysis. Biophysical Journal, 2008. 94(2): p. L14-L16. 
304. Stringari, C., et al., Phasor approach to fluorescence lifetime microscopy distinguishes different metabolic states of germ cells in a live tissue. Proceedings of the National Academy of Sciences of the United States of America, 2011. 108(33): p. 13582-13587.

305. Bacia, K., S.A. Kim, and P. Schwille, Fluorescence cross-correlation spectroscopy in living cells. Nature Methods, 2006. 3(2): p. 83-89.

306. Reits, E.A.J. and J.J. Neefjes, From fixed to FRAP: measuring protein mobility and activity in living cells. Nature Cell Biology, 2001. 3(6): p. E145-E147.

307. Chalfie, M., et al., Green fluorescent protein as a marker for gene expression. Science, 1994. 263(5148): p. 802-805.

308. Giepmans, B.N.G., et al., Review - The fluorescent toolbox for assessing protein location and function. Science, 2006. 312(5771): p. 217-224.

309. Dean, K.M. and A.E. Palmer, Advances in fluorescence labeling strategies for dynamic cellular imaging. Nature Chemical Biology, 2014. 10: p. 512-523.

310. Kentner, D. and V. Sourjik, Use of Fluorescence Microscopy to Study Intracellular Signaling in Bacteria, in Annual Review of Microbiology, Vol 64, 2010, S. Gottesman and C.S. Harwood, Editors. 2010. p. 373-390.

311. Mettetal, J.T., et al., Predicting stochastic gene expression dynamics in single cells. Proceedings of the National Academy of Sciences of the United States of America, 2006. 103(19): p. 7304-7309.

312. Acar, M., A. Becskei, and A. van Oudenaarden, Enhancement of cellular memory by reducing stochastic transitions. Nature, 2005. 435(7039): p. 228-232.

313. Kohlwein, S.D., The beauty of the yeast: Live cell microscopy at the limits of optical resolution. Microscopy Research and Technique, 2000. 51(6): p. 511-529.

314. Rafelski, S.M., et al., Mitochondrial Network Size Scaling in Budding Yeast. Science, 2012. 338(6108): p. 822-824.

315. Wilfling, F., et al., Triacylglycerol Synthesis Enzymes Mediate Lipid Droplet Growth by Relocalizing from the ER to Lipid Droplets. Developmental Cell, 2013. 24(4): p. 384399.

316. Nicoletti, I., et al., A rapid and simple method for measuring thymocyte apoptosis by propidium iodide staining and flow cytometry. Journal of Immunological Methods, 1991. 139(2): p. 271-279.

317. Sala-Newby, G.B., et al., Bioluminescent and Chemiluminescent Indicators for Molecular Signalling and Function in Living Cells. 2nd ed. Fluorescent and Luminescent Probes for Biological Activity ed. W.T. Mason. 1999: Elsevier.

318. Gaffield, M.A. and W.J. Betz, Imaging synaptic vesicle exocytosis and endocytosis with FM dyes. Nature Protocols, 2006. 1(6): p. 2916-2921. 
319. Govender, T., et al., BODIPY staining, an alternative to the Nile Red fluorescence method for the evaluation of intracellular lipids in microalgae. Bioresource Technology, 2012. 114: p. 507-511.

320. Herms, A., et al., Cell-to-Cell Heterogeneity in Lipid Droplets Suggests a Mechanism to Reduce Lipotoxicity. Current Biology, 2013. 23(15): p. 1489-1496.

321. Okumoto, S., A. Jones, and W.B. Frommer, Quantitative Imaging with Fluorescent Biosensors. Annual Review of Plant Biology, Vol 63, 2012. 63: p. 663-706.

322. Rudolf, R., et al., Looking forward to seeing calcium. Nature Reviews Molecular Cell Biology, 2003. 4(7): p. 579-586.

323. Schallmey, M., et al., Looking for the pick of the bunch: high-throughput screening of producing microorganisms with biosensors. Current Opinion in Biotechnology, 2014. 26: p. 148-154.

324. Bassnett, S., L. Reinisch, and D.C. Beebe, Intracellular pH measurement using single excitation - dual emission fluorescence ratios. American Journal of Physiology, 1990. 258(1): p. C171-C178.

325. Vanaelst, L., et al., Molecular cloning of a gene involved in glucose sensing in the yeast Saccharomyces cerevisiae. Molecular Microbiology, 1993. 8(5): p. 927-943.

326. Ungerboeck, B., et al., Microfluidic oxygen imaging using integrated optical sensor layers and a color camera. Lab on a Chip, 2013. 13(8): p. 1593-1601.

327. Dragavon, J., et al., A cellular isolation system for real-time single-cell oxygen consumption monitoring. Journal of the Royal Society Interface, 2008. 5: p. S151-S159.

328. Molter, T.W., et al., A microwell array device capable of measuring single-cell oxygen consumption rates. Sensors and Actuators B-Chemical, 2009. 135(2): p. 678-686.

329. Kalyuzhnaya, M.G., M.E. Lidstrom, and L. Chistoserdova, Real-time detection of actively metabolizing microbes by redox sensing as applied to methylotroph populations in Lake Washington. Isme Journal, 2008. 2(7): p. 696-706.

330. Konopka, M.C., et al., Single cell methods for methane oxidation analysis. Methods in enzymology, 2011. 495: p. 149-66.

331. Belousov, V.V., et al., Genetically encoded fluorescent indicator for intracellular hydrogen peroxide. Nature Methods, 2006. 3(4): p. 281-286.

332. Whitaker, M., Genetically Encoded Probes for Measurement of Intracellular Calcium, in Calcium in Living Cells, M. Whitaker, Editor. 2010. p. 153-182.

333. Mustafi, N., et al., Application of a Genetically Encoded Biosensor for Live Cell Imaging of L-Valine Production in Pyruvate Dehydrogenase Complex-Deficient Corynebacterium glutamicum Strains. Plos One, 2014. 9(1). 
334. Schendzielorz, G., et al., Taking Control over Control: Use of Product Sensing in Single Cells to Remove Flux Control at Key Enzymes in Biosynthesis Pathways. Acs Synthetic Biology, 2014. 3(1): p. 21-29.

335. Reymond, J.-L., V.S. Fluxa, and N. Maillard, Enzyme assays. Chemical Communications, 2009(1): p. 34-46.

336. Bratosin, D., et al., Novel fluorescence assay using calcein-AM for the determination of human erythrocyte viability and aging. Cytometry Part A, 2005. 66A(1): p. 78-84.

337. O'Brien, J., et al., Investigation of the Alamar Blue (resazurin) fluorescent dye for the assessment of mammalian cell cytotoxicity. European Journal of Biochemistry, 2000. 267(17): p. 5421-5426.

338. Olsen, M.J., et al., Function-based isolation of novel enzymes from a large library. Nature Biotechnology, 2000. 18(10): p. 1071-1074.

339. Zhu, A., R. Romero, and H.R. Petty, Amplex UltraRed enhances the sensitivity of fluorimetric pyruvate detection. Analytical Biochemistry, 2010. 403(1-2): p. 123-125.

340. Eyer, K., et al., Implementing Enzyme-Linked Immunosorbent Assays on a Microfluidic Chip To Quantify Intracellular Molecules in Single Cells. Analytical Chemistry, 2013. 85(6): p. 3280-3287.

341. Wang, D. and S. Bodovitz, Single cell analysis: the new frontier in 'omics'. Trends in Biotechnology, 2010. 28(6): p. 281-290.

342. Rubakhin, S.S., E.J. Lanni, and J.V. Sweedler, Progress toward single cell metabolomics. Current Opinion in Biotechnology, 2013. 24(1): p. 95-104.

343. Heinemann, M. and R. Zenobi, Single cell metabolomics. Current Opinion in Biotechnology, 2011. 22(1): p. 26-31.

344. Walker, B.N., et al., Metabolic Differences in Microbial Cell Populations Revealed by Nanophotonic Ionization. Angewandte Chemie-International Edition, 2013. 52(13): p. 3650-3653.

345. Mizuno, H., et al., Live single-cell video-mass spectrometry for cellular and subcellular molecular detection and cell classification. Journal of Mass Spectrometry, 2008. 43(12): p. $1692-1700$.

346. Urban, P.L., et al., High-density micro-arrays for mass spectrometry. Lab on a Chip, 2010. 10(23): p. 3206-3209.

347. Ibanez, A.J., et al., Mass spectrometry-based metabolomics of single yeast cells. Proceedings of the National Academy of Sciences of the United States of America, 2013. 110(22): p. 8790-8794. 
348. Zimmerman, T.A., S.S. Rubakhin, and J.V. Sweedler, MALDI Mass Spectrometry Imaging of Neuronal Cell Cultures. Journal of the American Society for Mass Spectrometry, 2011. 22(5): p. 828-836.

349. Lechene, C.P., et al., Quantitative imaging of nitrogen fixation by individual bacteria within animal cells. Science, 2007. 317(5844): p. 1563-1566.

350. Kraft, M.L., et al., Phase separation of lipid membranes analyzed with high-resolution secondary ion mass spectrometry. Science, 2006. 313(5795): p. 1948-1951.

351. Doughty, D.M., et al., Probing the Subcellular Localization of Hopanoid Lipids in Bacteria Using NanoSIMS. Plos One, 2014. 9(1).

352. Rubakhin, S.S., et al., Profiling metabolites and peptides in single cells. Nature Methods, 2011. 8(4): p. S20-S29.

353. Lee, S.C., et al., Subcellular in vivo H-1 MR spectroscopy of Xenopus laevis oocytes. Biophysical Journal, 2006. 90(5): p. 1797-1803.

354. Grant, S.C., et al., NMR spectroscopy of single neurons. Magnetic Resonance in Medicine, 2000. 44(1): p. 19-22.

355. Maguire, Y., et al., Ultra-small-sample molecular structure detection using microslot waveguide nuclear spin resonance. Proceedings of the National Academy of Sciences of the United States of America, 2007. 104(22): p. 9198-9203.

356. Bart, J., et al., A Microfluidic High-Resolution NMR Flow Probe. Journal of the American Chemical Society, 2009. 131(14): p. 5014-+.

357. Labhsetwar, P., et al., Heterogeneity in protein expression induces metabolic variability in a modeled Escherichia coli population. Proceedings of the National Academy of Sciences of the United States of America, 2013. 110(34): p. 14006-14011.

358. Carlquist, M., et al., Physiological heterogeneities in microbial populations and implications for physical stress tolerance. Microbial Cell Factories, 2012. 11.

359. Smith, C., Two microscopes are better than one. Nature, 2012. 492(7428): p. 293-297.

360. Saka, S.K., et al., Correlated optical and isotopic nanoscopy. Nature Communications, 2014. 5.

361. Barnett, D., et al., CD4 immunophenotyping in HIV infection. Nature Reviews Microbiology, 2008. 6(11): p. S7-S15.

362. Pan, J., et al., Quantitative tracking of the growth of individual algal cells in microdroplet compartments. Integrative Biology, 2011. 3(10): p. 1043-1051.

363. Rosch, P., et al., Raman spectroscopic identification of single yeast cells. Journal of Raman Spectroscopy, 2005. 36(5): p. 377-379. 
Figure 1

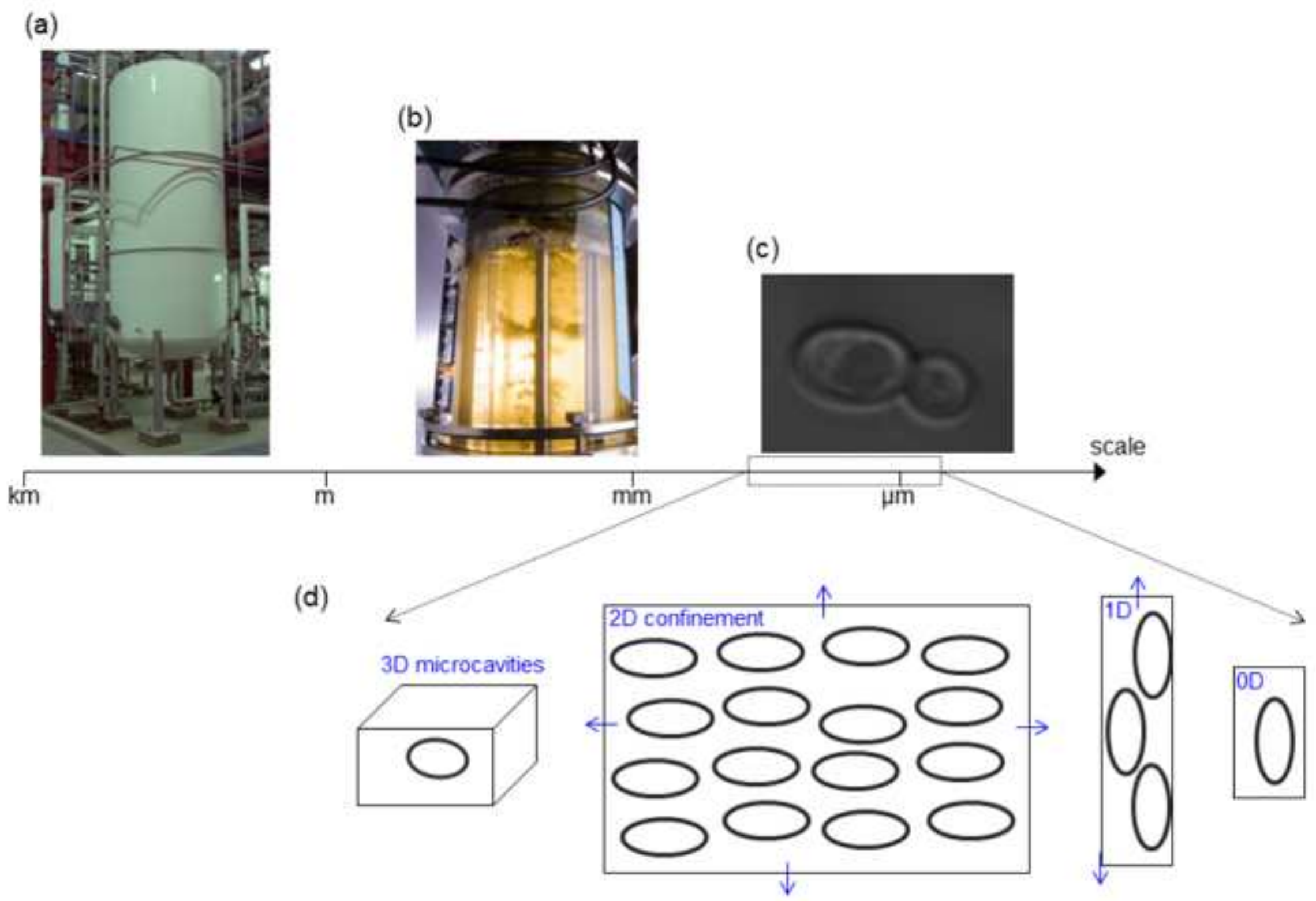




\section{Figure 2}
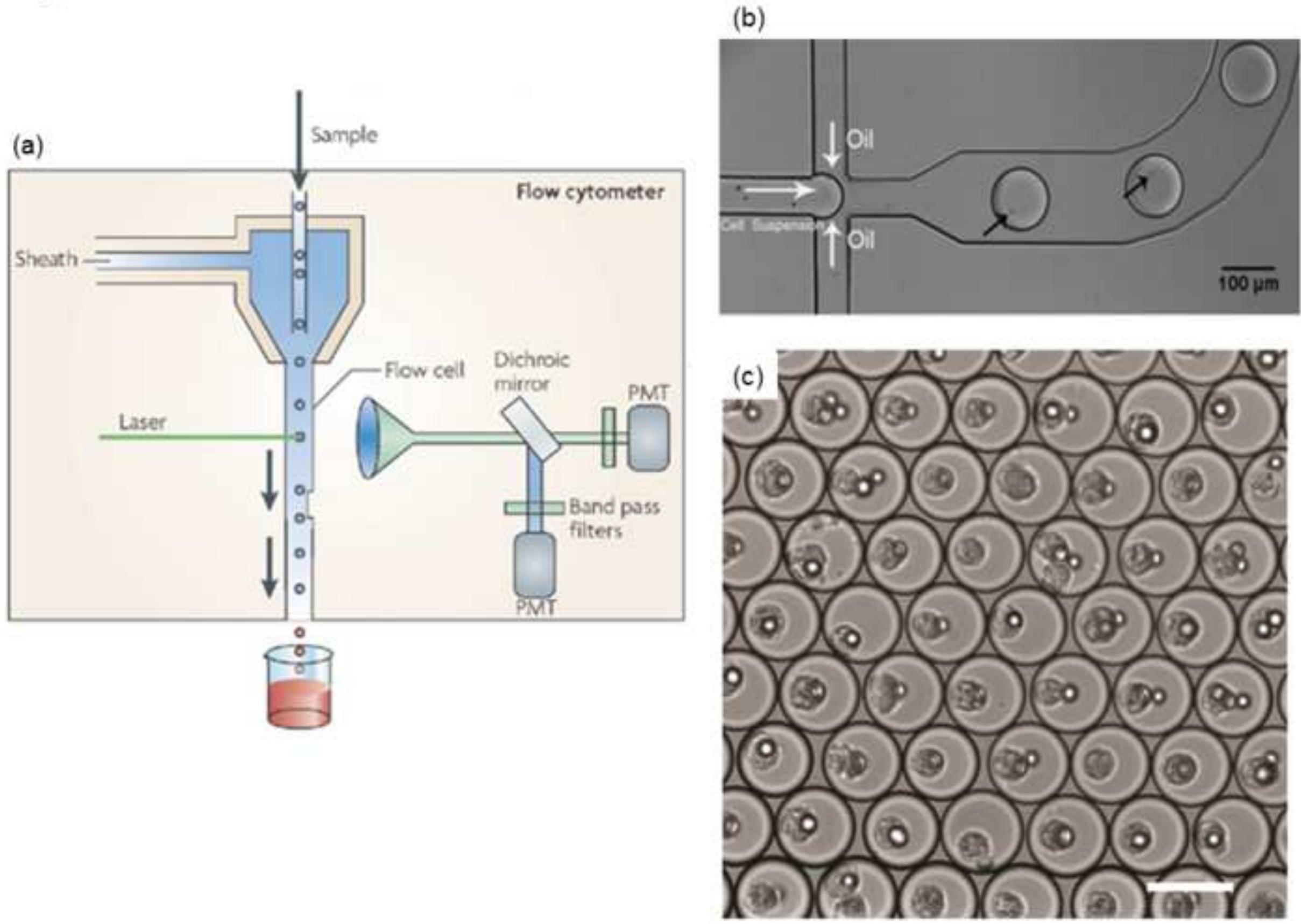
Figure 3

(a)

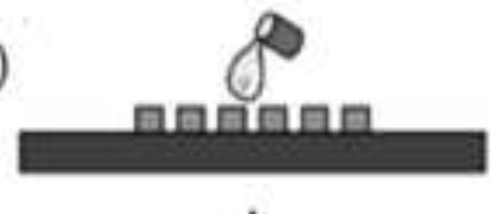

$+$

(b)

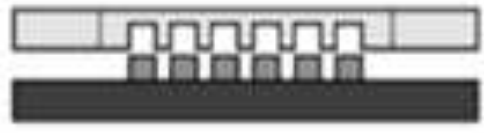

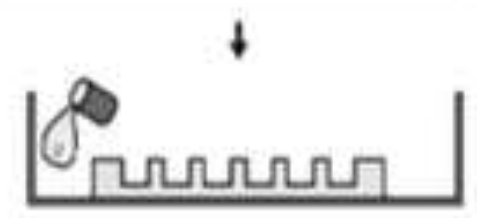

$+$

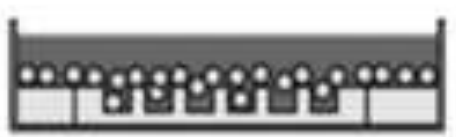

$\downarrow$

|pmand

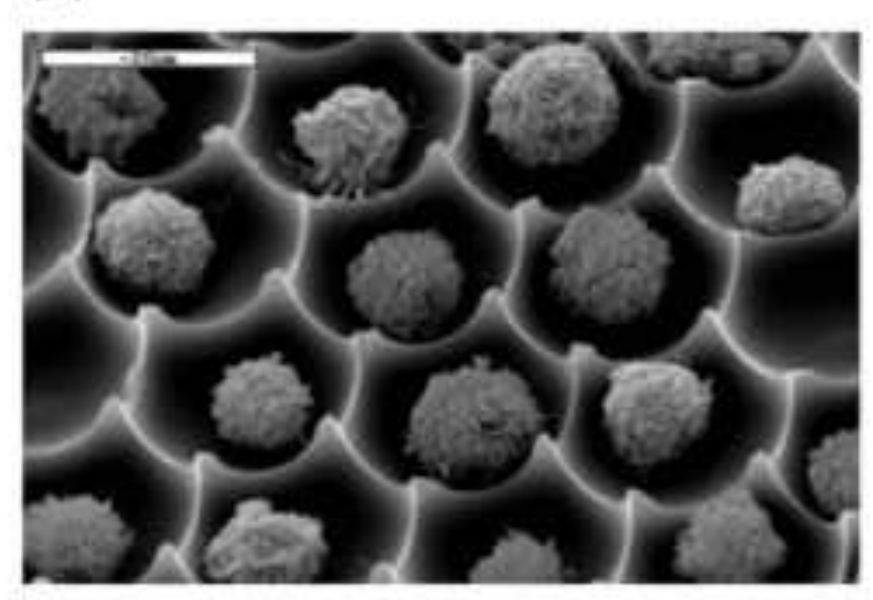

(c)

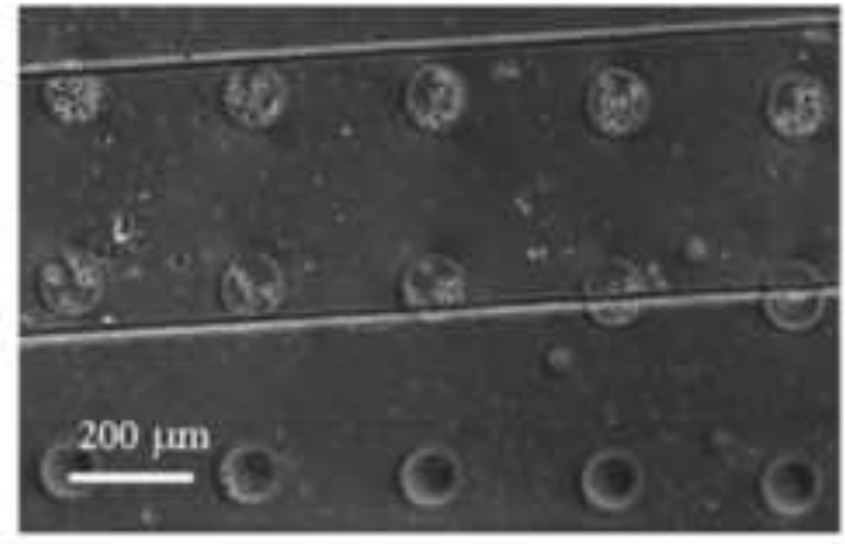




\section{Figure 4}
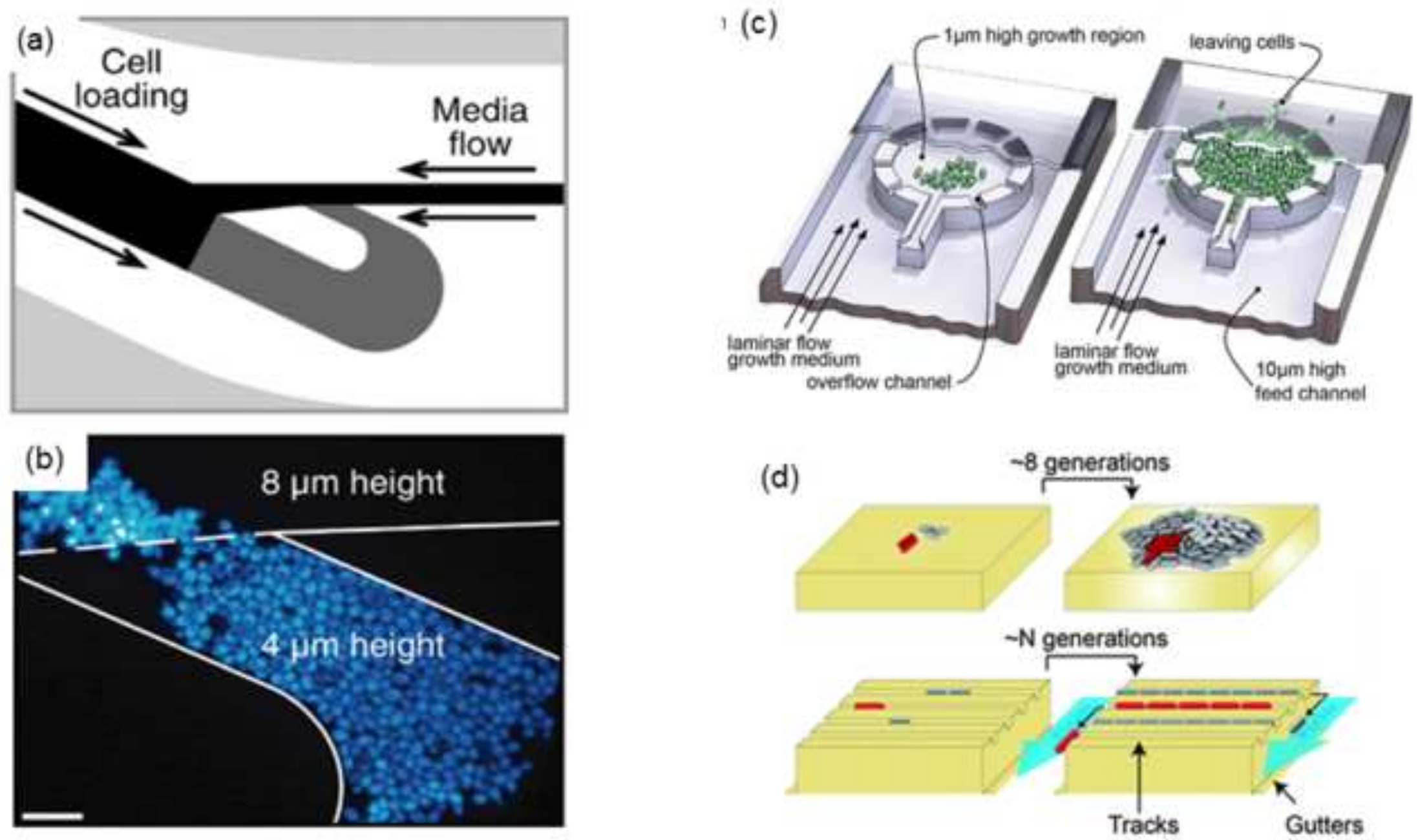


\section{Figure 5}

(a)

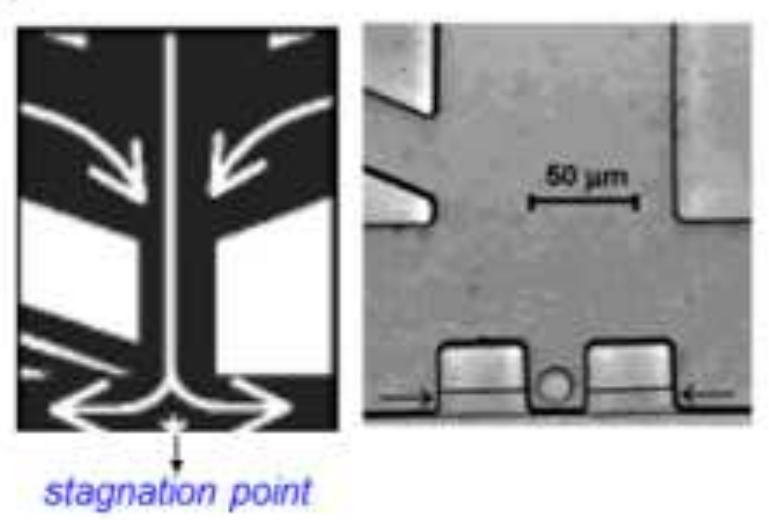

(b)
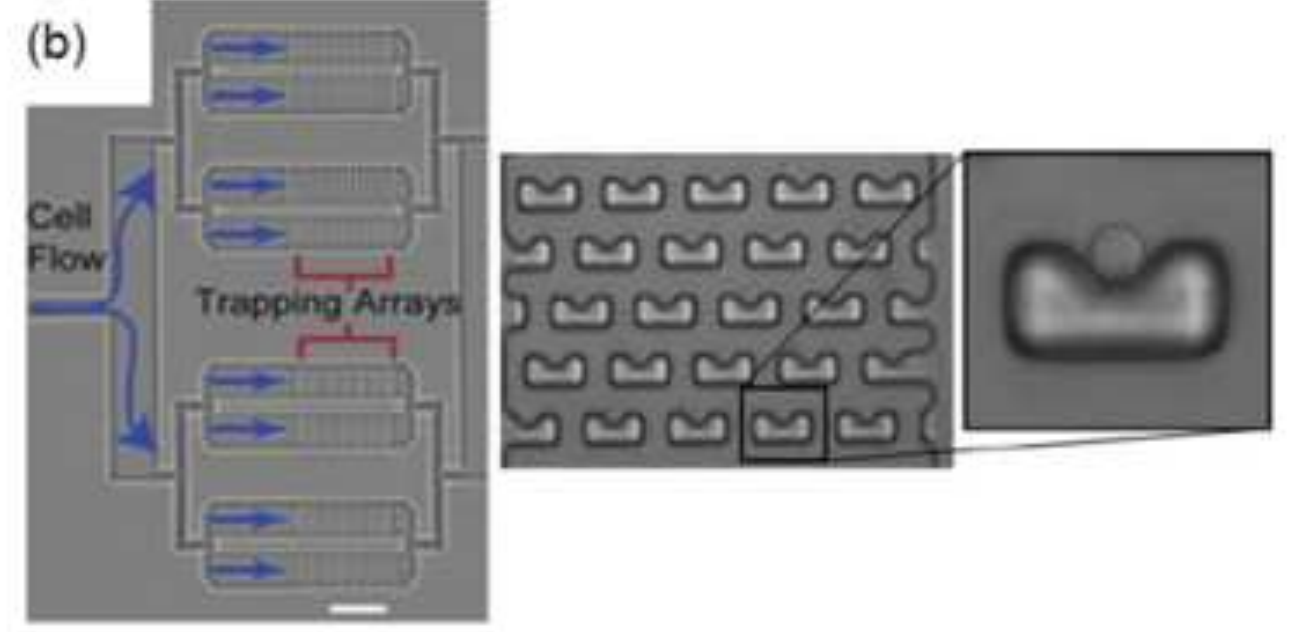

(c)

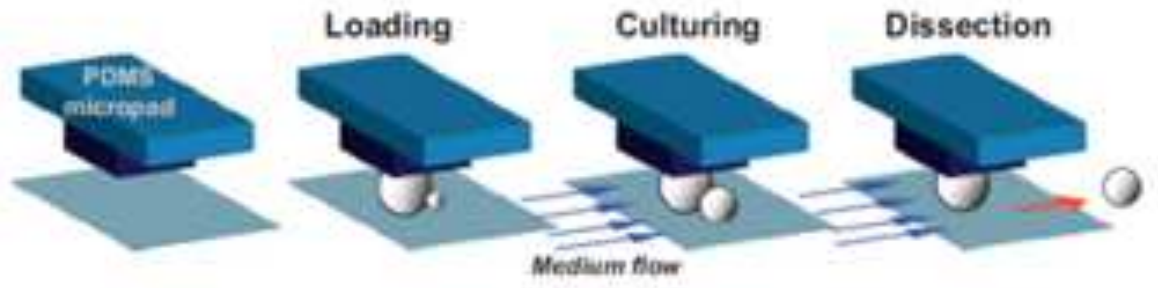

(d)

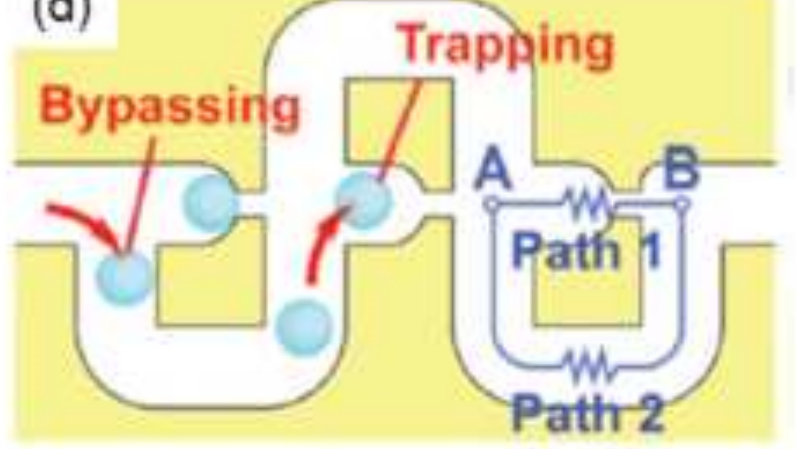




\section{Figure 6}
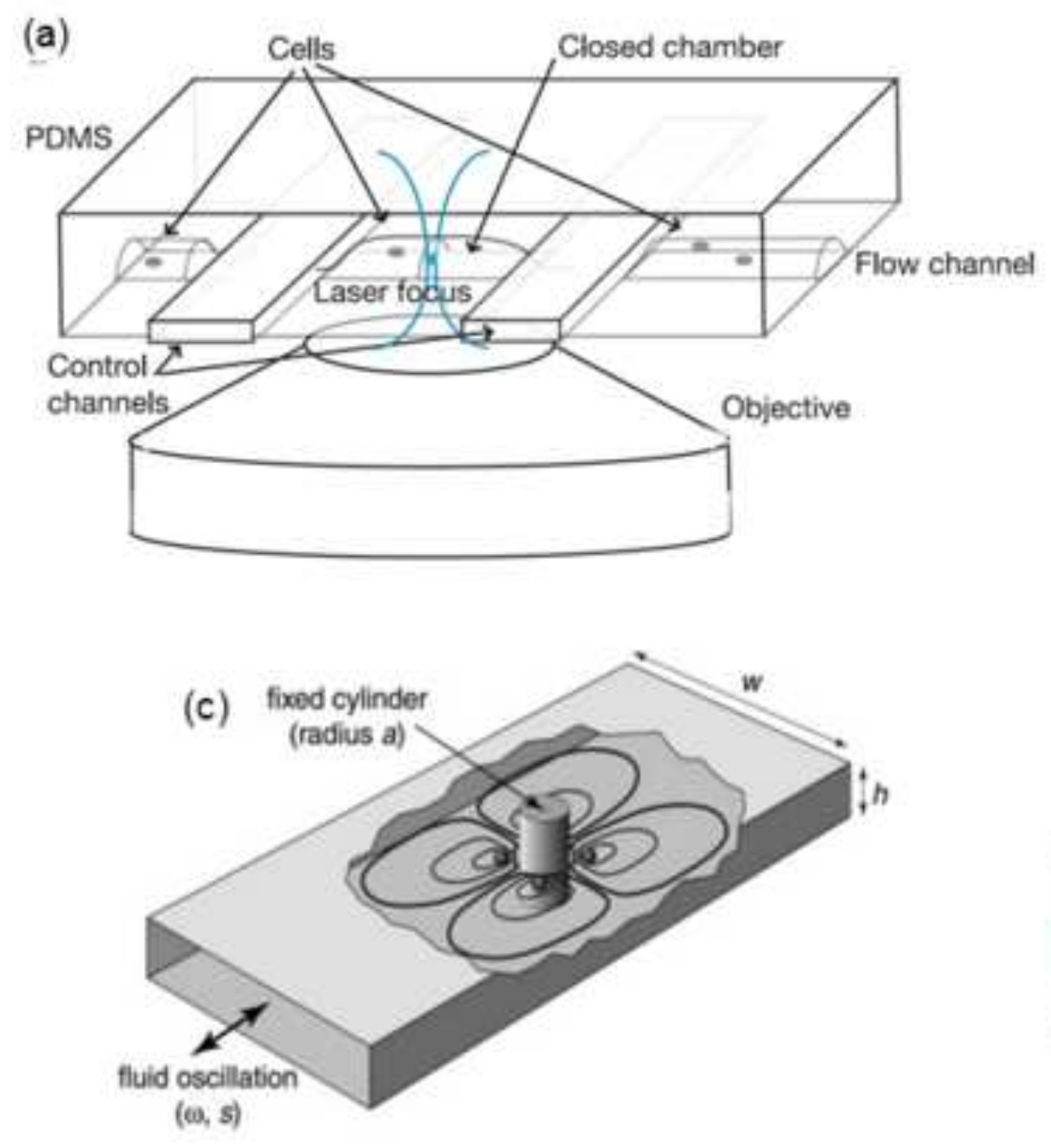

(b)
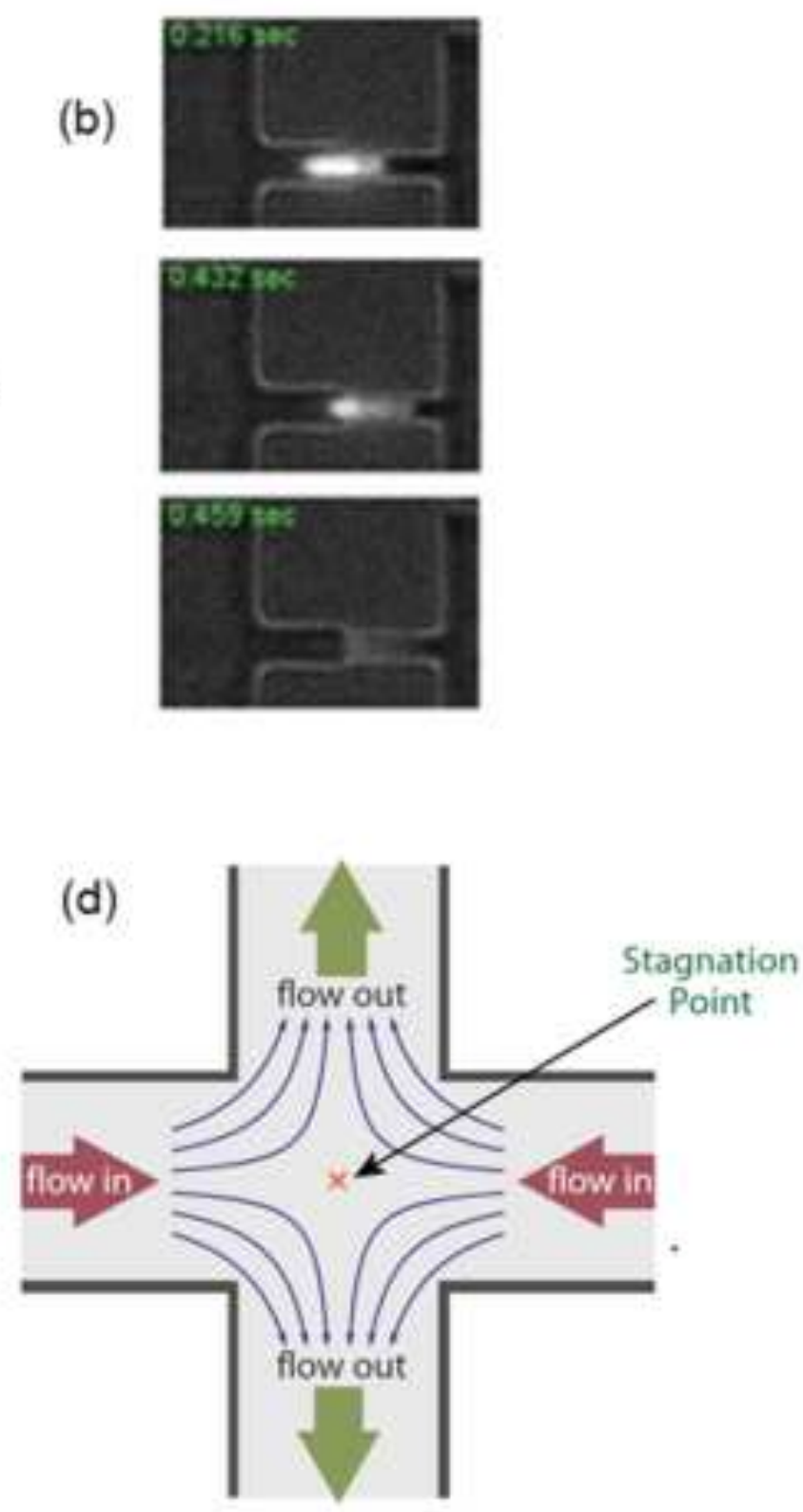


\section{Figure 7}

(a)

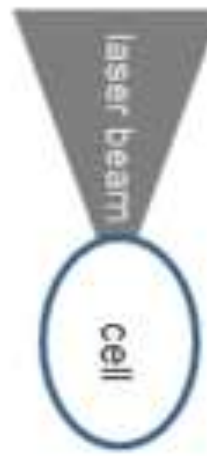

(b)

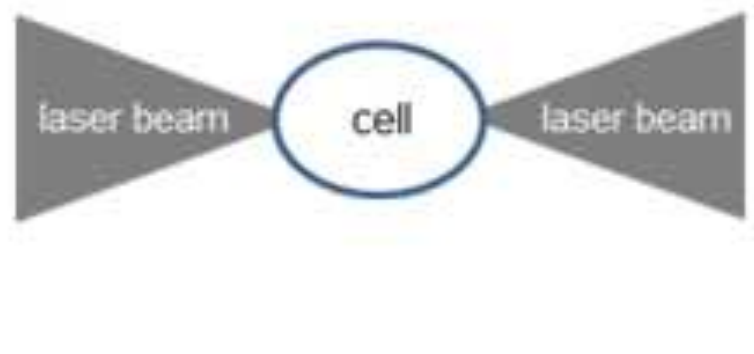

(d)

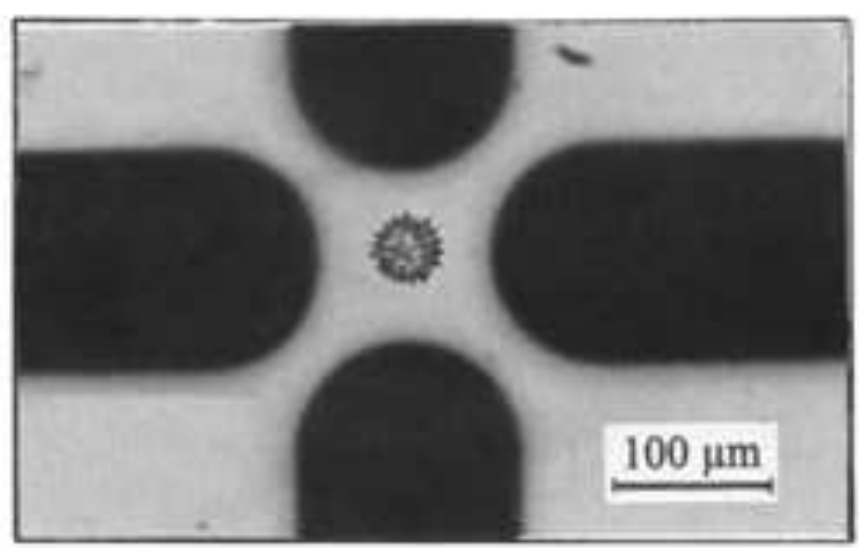

(c)
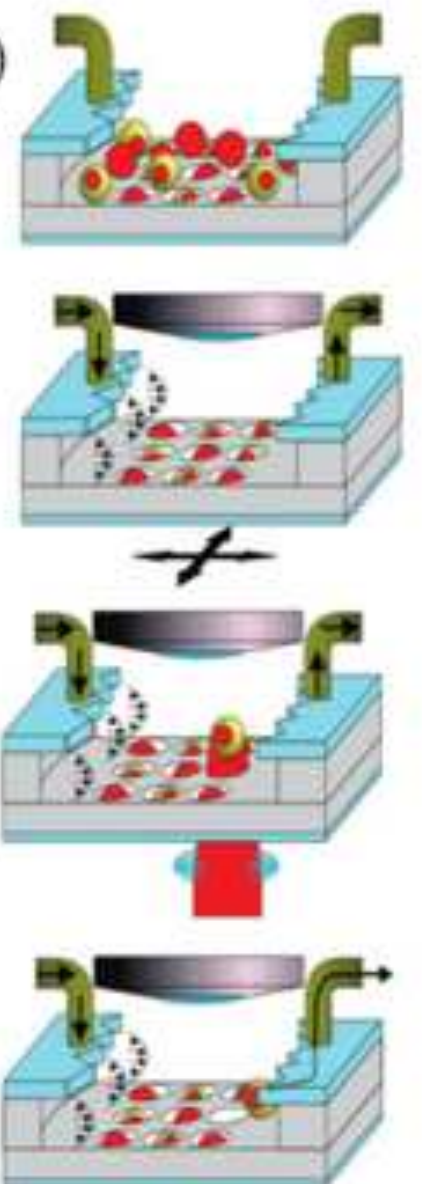

(e)
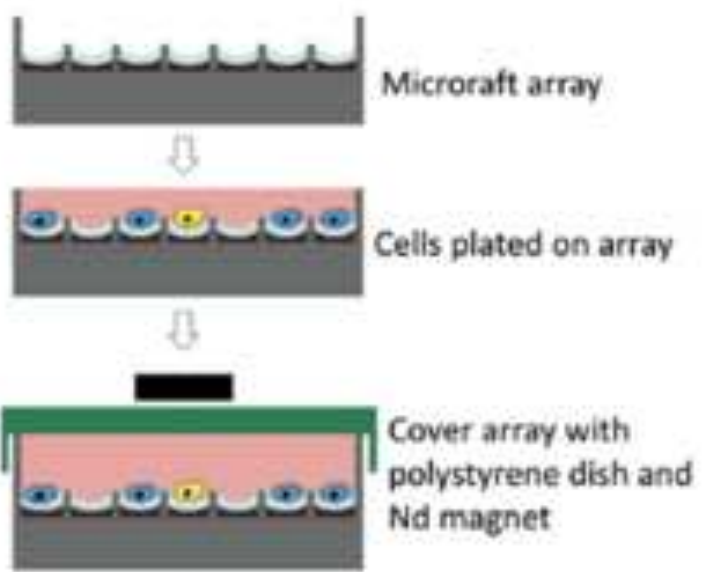

8

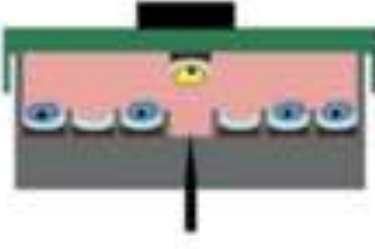

Released microratt magnetically collectec on polystyrene dish

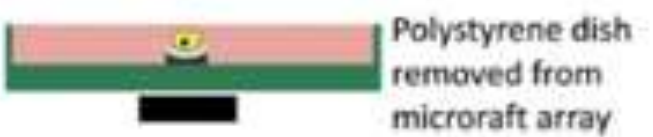


Figure 8
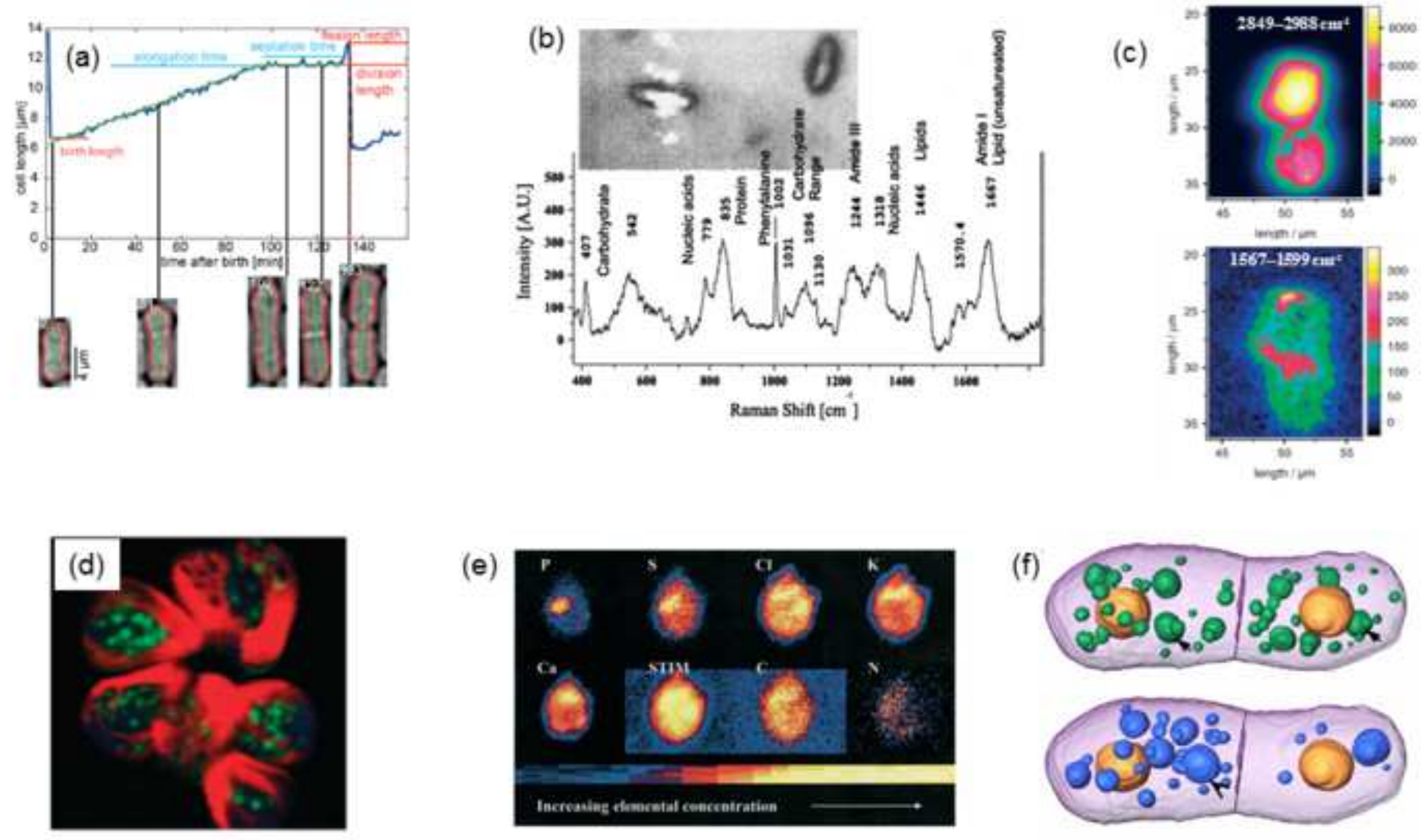

(e)

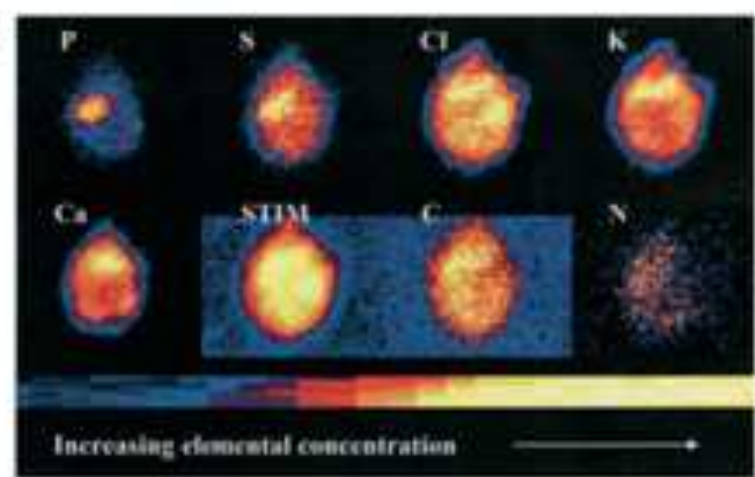

(f)

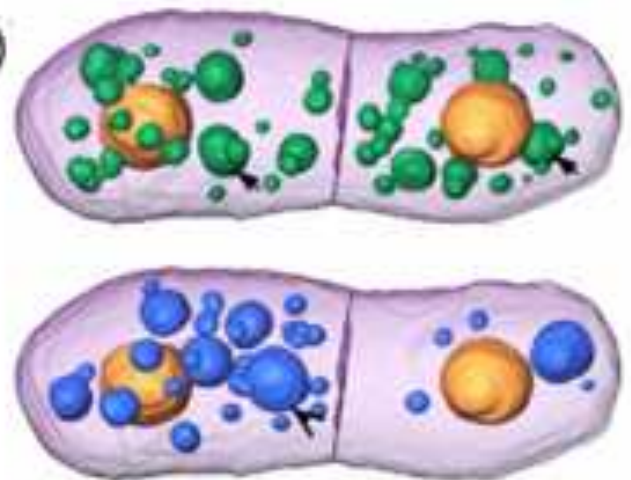




\section{Figure 9}

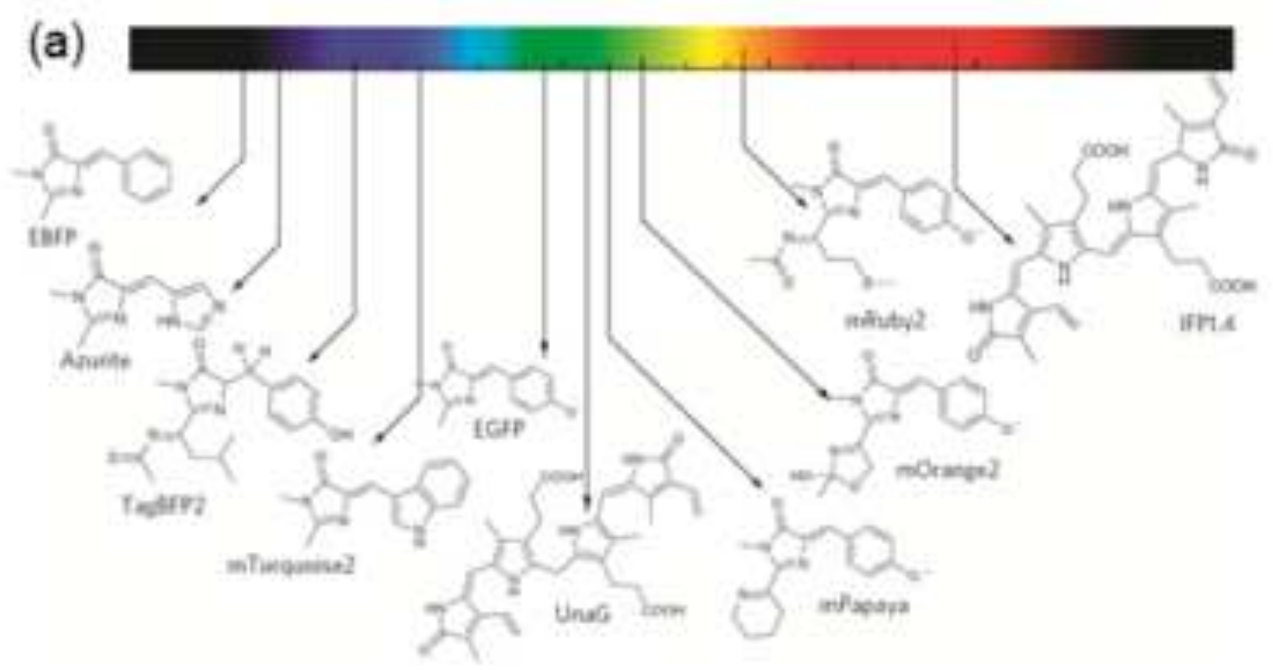

(b)

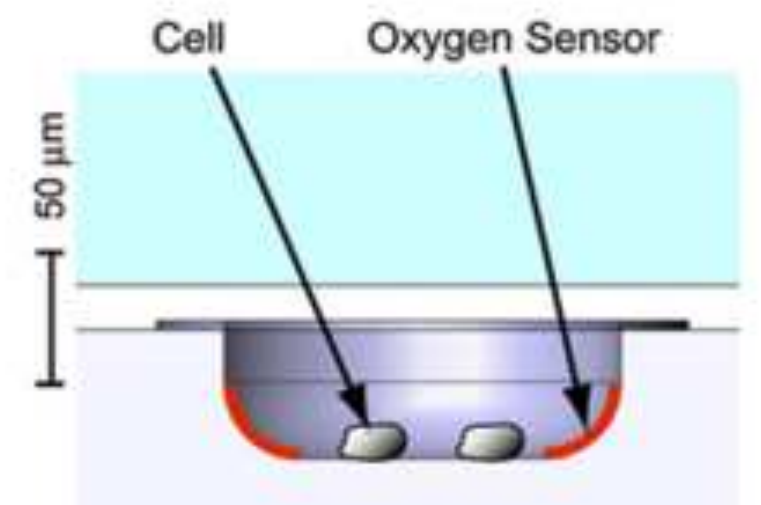

(c)

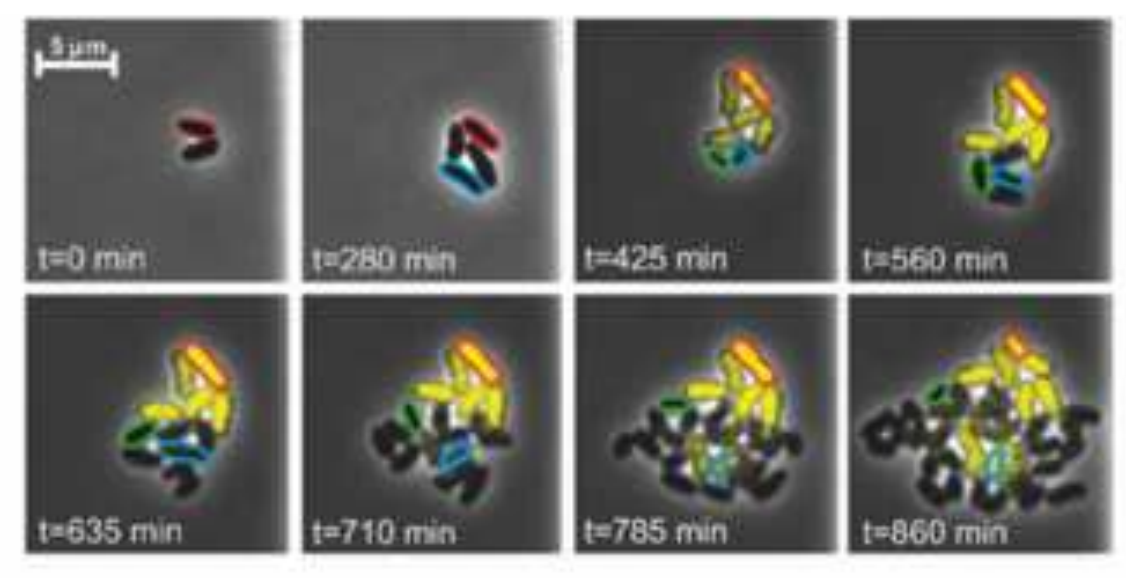

(d)

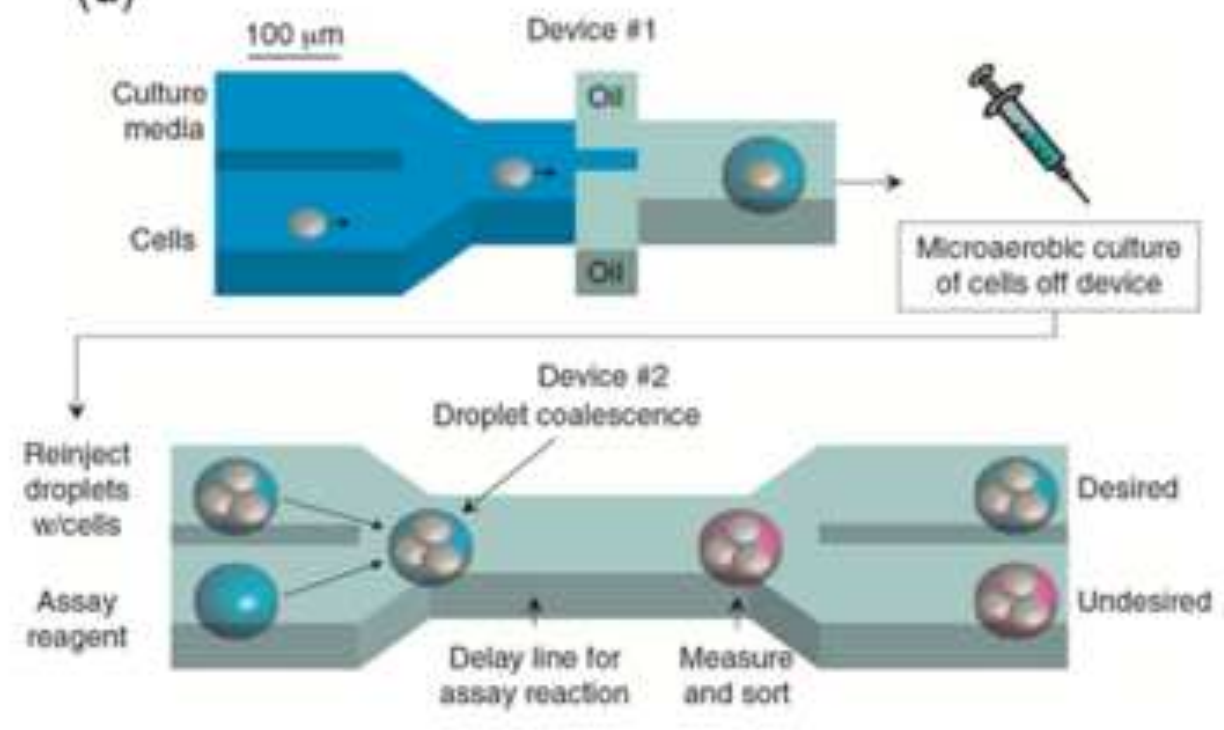


Figure 10
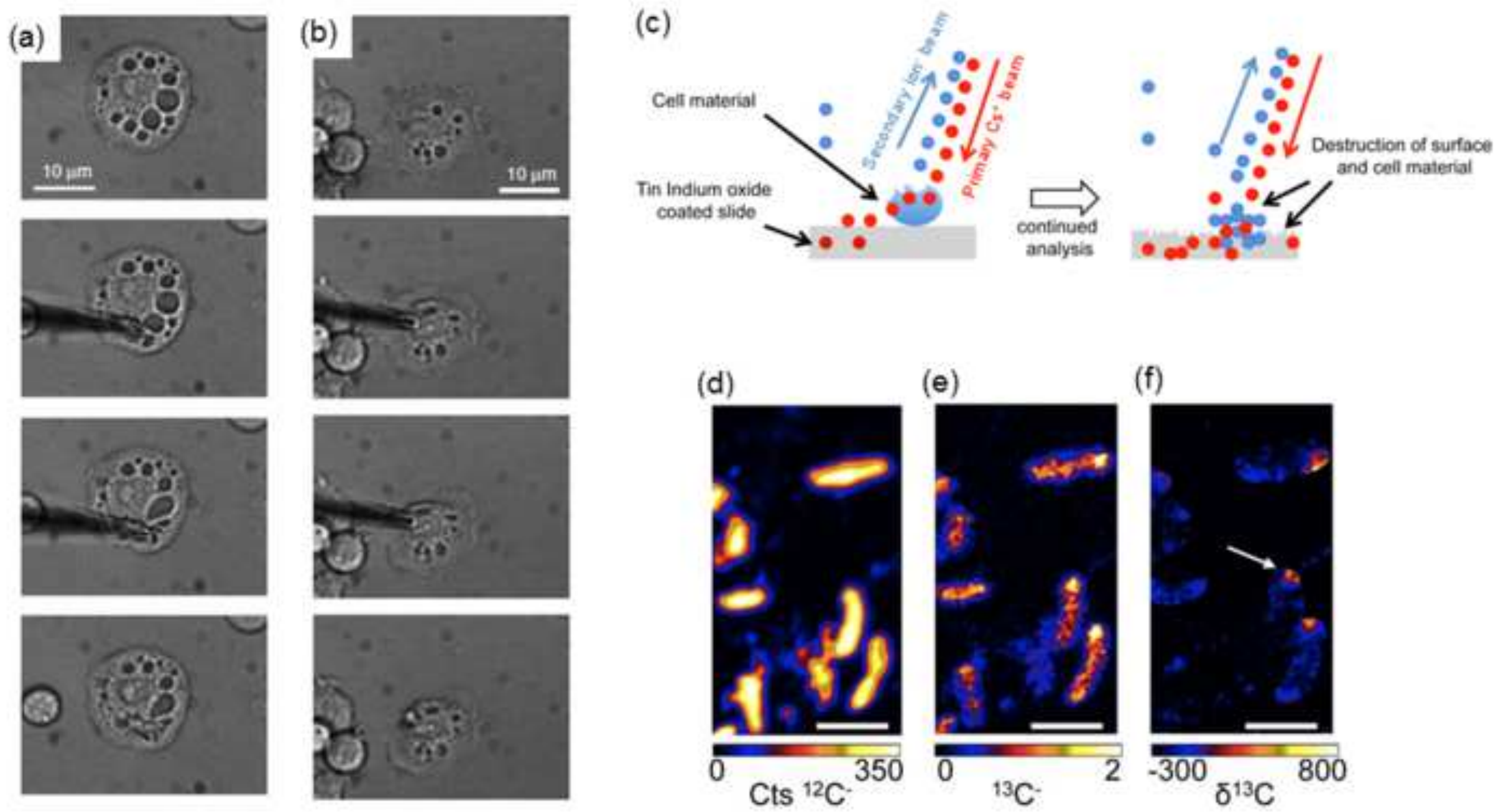

(e)

(f)
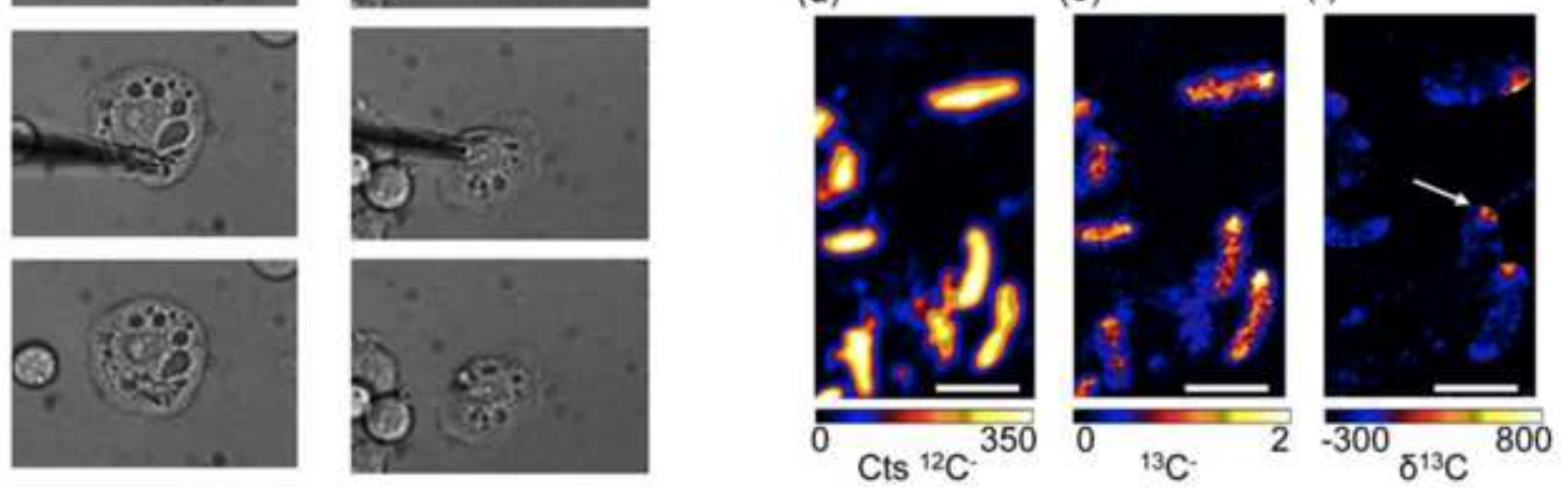


\begin{tabular}{|ccccccccc}
\hline method & type & recovery & capacity & expertise & micrenvironment & surface noise & section/references \\
\hline flow-cytometry & flow-through & + & $10^{4}-10^{5}$ cells & + & not available & + & $2.1 .1 /[22-39]$ \\
microfluidic droplets & flow-through & + & $10^{3}-10^{4}$ cells & - & not available & + & $2.1 .2 /[40-63]$ \\
microwell & permanent & - & $10^{2}-10^{3}$ cells & + & - & - & $2.2 .1 /[64-75]$ \\
microchemostats & permanent & - & $10^{2}-10^{3}$ cells & - & microfluidics & - & $2.1 .2 /[76-81]$ \\
2D confinement & permanent & - & $10^{2}-10^{3}$ cells & - & microfluidics & - & $2.2 .2 /[82-92]$ \\
1D confinement & permanent & - & $10^{2}-10^{3}$ cells & - & microfluidics & - & $2.2 .3 /[93-100]$ \\
axial percolation & permanent & - & $10^{1}-10^{3}$ cells & - & microfluidics & - & $2.2 .4 /[103-109]$ \\
lateral percolation & permanent & - & $10^{1}-10^{3}$ cells & - & microfluidics & - & $2.2 .4 /[110-115]$ \\
hydrogels & permanent & - & $10^{1}-10^{3}$ cells & + & microfluidics & - & $2.2 .4 /[116-125]$ \\
surface functionalization & permanent & - & $10^{1}-10^{3}$ cells & + & microfluidics & - & $2.2 .4 /[126-149]$ \\
pneumatic microcavities & dynamic & + & $10^{0}-10^{2}$ cells & - & microfluidics & - & $2.3 .1 /[150-155]$ \\
hydrodynamic & dynamic & + & $10^{0}-10^{2}$ cells & - & microfluidics & - & $2.3 .1 /[106,156-161]$ \\
acoustic & dynamic & + & $10^{0}-10^{2}$ cells & - & microfluidics & - & $2.3 .1 /[162-166]$ \\
optical tweezers & dynamic & + & $10^{0}-10^{2}$ cells & + & microfluidics & + & $2.3 .2 /[167-174]$ \\
radiation pressure & dynamic & + & $10^{0}-10^{2}$ cells & - & microfluidics & + & $2.3 .2 /[175-180]$ \\
optoelectronic tweezers & dynamic & + & $10^{0}-10^{4}$ cells & + & microfluidics & - & $2.3 .2 /[181-184]$ \\
photothermal/catalytic & dynamic & + & serial & + & & - & - & $2.3 .2 /[110]$ \\
dielectrophoresis & dynamic & + & $10^{0}-10^{2}$ cells & - & microfluidics & - & $2.3 .3 /[187-195]$ \\
magnetic tweezers & dynamic & + & $10^{0}-10^{2}$ cells & + & microfluidics & - & $2.3 .4 /[196-200]$ \\
\hline
\end{tabular}

